\title{
Emerging avenues in immunotherapy for the management of malignant pleural mesothelioma
}

Steven G. Gray ${ }^{1,2,3^{*}}$ (D)

\begin{abstract}
Background: The role of immunotherapy in cancer is now well-established, and therapeutic options such as checkpoint inhibitors are increasingly being approved in many cancers such as non-small cell lung cancer (NSCLC). Malignant pleural mesothelioma (MPM) is a rare orphan disease associated with prior exposure to asbestos, with a dismal prognosis. Evidence from clinical trials of checkpoint inhibitors in this rare disease, suggest that such therapies may play a role as a treatment option for a proportion of patients with this cancer.

Main text: While the majority of studies currently focus on the established checkpoint inhibitors (CTLA4 and PD1/ PDL1), there are many other potential checkpoints that could also be targeted. In this review I provide a synopsis of current clinical trials of immunotherapies in MPM, explore potential candidate new avenues that may become future targets for immunotherapy and discuss aspects of immunotherapy that may affect the clinical outcomes of such therapies in this cancer.

Conclusions: The current situation regarding checkpoint inhibitors in the management of MPM whilst encouraging, despite impressive durable responses, immune checkpoint inhibitors do not provide a long-term benefit to the majority of patients with cancer. Additional studies are therefore required to further delineate and improve our understanding of both checkpoint inhibitors and the immune system in MPM. Moreover, many new potential checkpoints have yet to be studied for their therapeutic potential in MPM. All these plus the existing checkpoint inhibitors will require the development of new biomarkers for patient stratification, response and also for predicting or monitoring the emergence of resistance to these agents in MPM patients. Other potential therapeutic avenues such CAR-T therapy or treatments like oncolytic viruses or agents that target the interferon pathway designed to recruit more immune cells to the tumor also hold great promise in this hard to treat cancer.
\end{abstract}

\section{Background}

MPM is an aggressive inflammatory cancer associated with exposure to asbestos. Despite having been banned in the western world, current data from the US has shown that the rate of MPM in males has remained constant from 1994, while the rate of MPM in females has

\footnotetext{
*Correspondence: sgray@stjames.ie

1 Thoracic Oncology Research Group, Central Pathology Laboratory, CPL 30, TCDSJ Cancer Institute, St James's Hospital, Dublin D08 RX0X, Ireland Full list of author information is available at the end of the article
}

remained unchanged for decades [1]. Indeed, while the use of asbestos has declined in industrialized nations, asbestos is still being exported to developing nations [2, 3]. Moreover, environmental exposure is still widespread due to (a) previous industrial use; (b) its difficulty to remove; (c) natural deposits are being disturbed by human activities; and (d) housing proximity to these natural deposits $[1,4-7]$.

The economic burden for MPM is significant both at the level of total cost for hospital care $[8,9]$, and economic burden $[9,10]$. 
Clinically, if untreated, MPM has a median survival time of 6 months, and most patients die within 24 months of diagnosis. The current standard of care (SOC) is a combination of pemetrexed/raltitrexed and cisplatin chemotherapy) [11] is non-curative and results in a response rate of $\sim 40 \%$ [12], and there is no standard second line therapy once treatment fails. Recently, the addition of an anti- vascular endothelial growth factor (anti-VEGF) therapy (Bevacizumab) has been shown to enhance OS when given in the first line setting [13]. And whilst this therapeutic combination is now the new standard of care in France [14], it has not yet been approved by the FDA, issues with cost and lack of reimbursement prevent it from being added to the SOC in many countries, and other anti-angiogenic combinations have not been successful [15].

The power of the human immune system to prevent cancer (often described as immune-surveillance) was first mooted by Ehrlich in 1909 [16, 17]. One of the mechanisms used by cancer cells to evade immune surveillance involves a series of surface regulatory markers (called checkpoint molecules), and has led to the development of checkpoint inhibitors for cancer therapy, an area of active investigation in MPM. Other prominent new treatment options emerging in MPM (and other cancers) involve cancer immunotherapy, a situation where the patient's own immune system (antibodies, cells, cytokines, etc.) is exploited to eliminate tumor cells $[17,18]$. In the following review we examine some of the current clinical studies of immunotherapies in mesothelioma, explore some of the issues potentially linked to lack of objective responses, and discuss alternative immunotherapy targets which may translate into mesothelioma clinical trials moving forwards.

\section{Immunotherapy in MPM in the historical setting}

Historically, immunotherapy in mesothelioma is not new, and studies involving this cancer have been attempted for over 25 years [19]. Examples of early trials in this arena predominantly used Interleukin-2 (IL-2) and Tumor Necrosis Factor alpha (TNF- $\alpha$ ), were ineffective and suffered particularly from a lack of scalability and logistical issues $[19,20]$. Some encouraging clinical responses were observed for patients with good performance status [21] while more recent studies in animal models suggest that direct injection of IL-2 plus an agonist anti-CD40 antibody induces regression of large mesothelioma tumors through a mechanism involving natural killer (NK) cells driven acquisition and/or maintenance of systemic immunity and long-term effector/memory anti-mesothelioma responses [22].

Some of the earliest trials involved the infusion of interferon (IFN) gamma to treat malignant pleural effusions [23, 24], oftentimes with complete responses in Stage I patients [24]. Follow up studies using intrapleural infusion of interferon-gamma in a larger cohort of $(\mathrm{n}-89)$ patients observed a $20 \%$ overall response rate with most responses in early stage disease especially if the tumor was confined to the parietal or diaphragmatic pleura [25]. Whilst these and other studies of interferon therapy combined with chemotherapy regimens suggest that this strategy could be useful $[26,27]$ with median survival rates of approximately $8-12$ months, other studies found significant toxicities [28]. Later studies using intrapleurally infused autologous human activated macrophages combined with interferon gamma found limited antitumor activity [29], while a study involving debulking surgery coupled with interferon based immunotherapy also demonstrated limited overall survival benefit [30], suggesting that interferon therapy has limited clinical benefit in MPM.

Another potential immunotherapy target for MPM involves Granulocyte macrophage colony-stimulating factor or GM-CSF, used as an immune-stimulatory adjuvant to elicit antitumor immunity [31,32]. Initial studies in MPM involved infusions of GM-CSF [33-35] but few or no responses were observed [34, 35], and high toxicity [33] or a poor OS (median survival of 7 months) were the outcomes. A small clinical trial $(n=22$ patients) was conducted involving a vaccination strategy comprising autologous mesothelioma tumor cell lysate combined with GM-CSF was conducted. The trial was found to be safe, and induced tumor specific immunity in $32 \%$ of patients, but saw only stable disease ad no tumor objective responses [36]. More recently, tumor derived GMCSF was shown to actually promote immunosuppression in mesothelioma suggesting that actually targeting this molecule may be more effective in augmenting immunotherapy in MPM [37].

\section{Checkpoint inhibitor immunotherapy within the neo-adjuvant setting}

Although not SOC, there is compelling evidence that a select subgroup of mesothelioma patients benefit from a surgery-based multimodal approach, particularly if they have an epithelioid histological subtype, lowervolume disease, and/or minimal to no nodal involvement [38]. In MPM microscopic complete resection is considered to not be achievable, and patients who have surgically resectable disease often undergo an aggressive multi-modality therapy for which the optimal combination therapy has not yet been identified [39]. Various taskforces have been set to explore the various options, and some proposed consensus reports have recently been published [40-42]. In this regard neoadjuvant immunotherapy prior to surgery has been 
mooted as an advantageous prospect in the management of solid tumors as they enhance T-cell activation the moment antigen is encountered, and encouraging findings from early-phase clinical trials in various cancers support this notion [43-45]. A series of Phase I/ II clinical trials involving neo-adjuvant immunotherapy prior to surgical resection have been initiated in MPM (Table 1) but as these trials are still running the results are not yet mature.

\section{Checkpoint inhibitor immunotherapy in the surgical setting}

Aside from the neo-adjuvant setting, there is one ongoing multicenter, randomized, controlled, open-label Phase II study which is designed to assess the efficacy of standard chemotherapy combined with nivolumab in the context of multimodal management of early-stage MPM (Table 1) [50]

\section{Checkpoint inhibitor immunotherapy within the front-line (first-line) setting}

A number of studies have been completed or are ongoing which aim to examine the potential utility of checkpoint inhibitor immunotherapy in the front-line setting. Several of these are ongoing (Table 2), but interim and published results from some of these trials as discussed by us and others $[47,48,51,52]$ suggest that checkpoint inhibitors will be important new agents in the frontline setting for the management of MPM. For example, interim results of PrE0505 (Table 2) demonstrate a median OS of 20.4 months, and a 1-year OS rate of $70.4 \%$ [52] with new trials such as DREAM3R (Table 3) initiated on the basis of these interim results.

Most recently, analysis of the Checkmate-743 trial (Table 2) has resulted in the FDA approval of a combination therapy of Nivolumab/Ipilimumab as a first line treatment for unresectable MPM [53, 54]. The median OS with this treatment was consistent between patients with epithelioid histology (18.7 months) and non-epithelioid histology (18.1 months) [53]. The OS benefit observed in the non-epithelioid subgroup for the checkpoint inhibitor combination versus standard chemotherapy is notable (18.7 months vs 8.8 months), but can be attributed to the established inferior effect of chemotherapy in the non-epithelioid subtype [53].

The approval of Nivolumab/Ipilimimab by the FDA as a front-line therapy for the treatment of MPM is greatly encouraging [54], and the results of the various ongoing trials will help improve the utility of checkpoint inhibitors in the front-line setting moving forwards.

\section{Checkpoint inhibitor immunotherapy within the salvage setting}

A large number of studies are also currently investigating the potential use of checkpoint inhibitors within the second or third-line (salvage therapy) setting, and are discussed in more detail in the following sections.

\section{Single agent checkpoint inhibitor studies}

Several clinical trials of checkpoint inhibitors as single agents have been completed in the salvage setting and are summarized in Table 3. In particular, the MERIT trial, a Phase II multi-center, open-label, uncontrolled, trial of patients within the second-line setting, observed an OS of 17.3 months which resulted in Nivolumab being approved by the Japanese Ministry of Health, Labor and Welfare for salvage therapy in MPM [65]. Despite this, several other single-agent trials of checkpoint inhibitors such as DETERMINE, PROMIS-MESO, JAVELIN or Nivo-Mes for example have had mixed results (Table 3) and these data have been reviewed extensively by us and others $[19,47,66]$. Another ongoing single institute phase II trial (IRB14-1381-NCT02399371) has reported interim results suggesting that checkpoint inhibitors show robust activity in the salvage setting, with a median OS of 11.5 months [64] (Table 3). Most recently, interim results from the Phase III trial CONFIRM trial (Table 3) have been presented [67]. In the interim results presented superiority for nivolumab over and above placebo was observed for OS with a hazard ratio of 0.72 $(p=0.018)$. The same was true for PFS with a hazard ratio of $0.61(p<0.001)$. Interestingly PD-L1 expression had no bearing on OS, whereas an epithelioid histology was found to have a significant survival advantage with a 12 month OS (40 vs. 26.7 months) with a hazard ratio of $0.71(p=0.021)$ [67]. Despite this, data from the Dutch expanded access program, suggest that in a real-world setting patients with recurrent malignant pleural mesothelioma, nivolumab did not provide the same benefits as observed in clinical trials with worse ORR and a median OS of only 6.7 months $[68,69]$.

\section{Combination checkpoint inhibitor studies in MPM}

Several studies have now combined checkpoint inhibitors in the salvage setting summarized in Table 4.

Two of these trials (MAPS2, NIBIT-Meso-1-Table 4) documented responses with a median OS of approximately 16 months for the combination arms [70, 71].

The INITIATE trial (Table 4) which had an estimated OS of approximately 12.7 months (Table 4) [72-74] along with the NivoMes trial (Table 3 ) were recently re-examined to complete a comprehensive immune cell profiling of samples [74], and the results demonstrated that the 


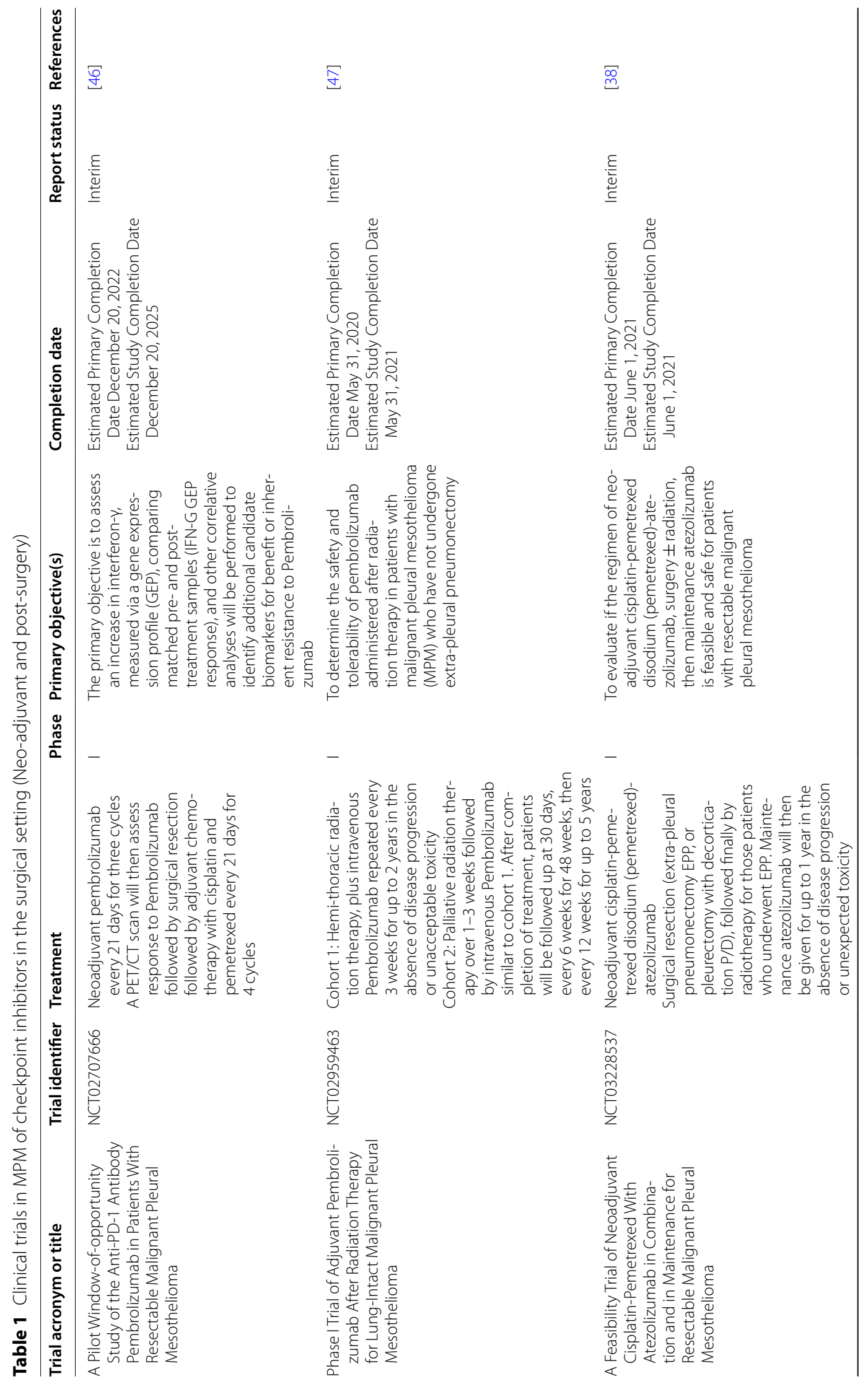




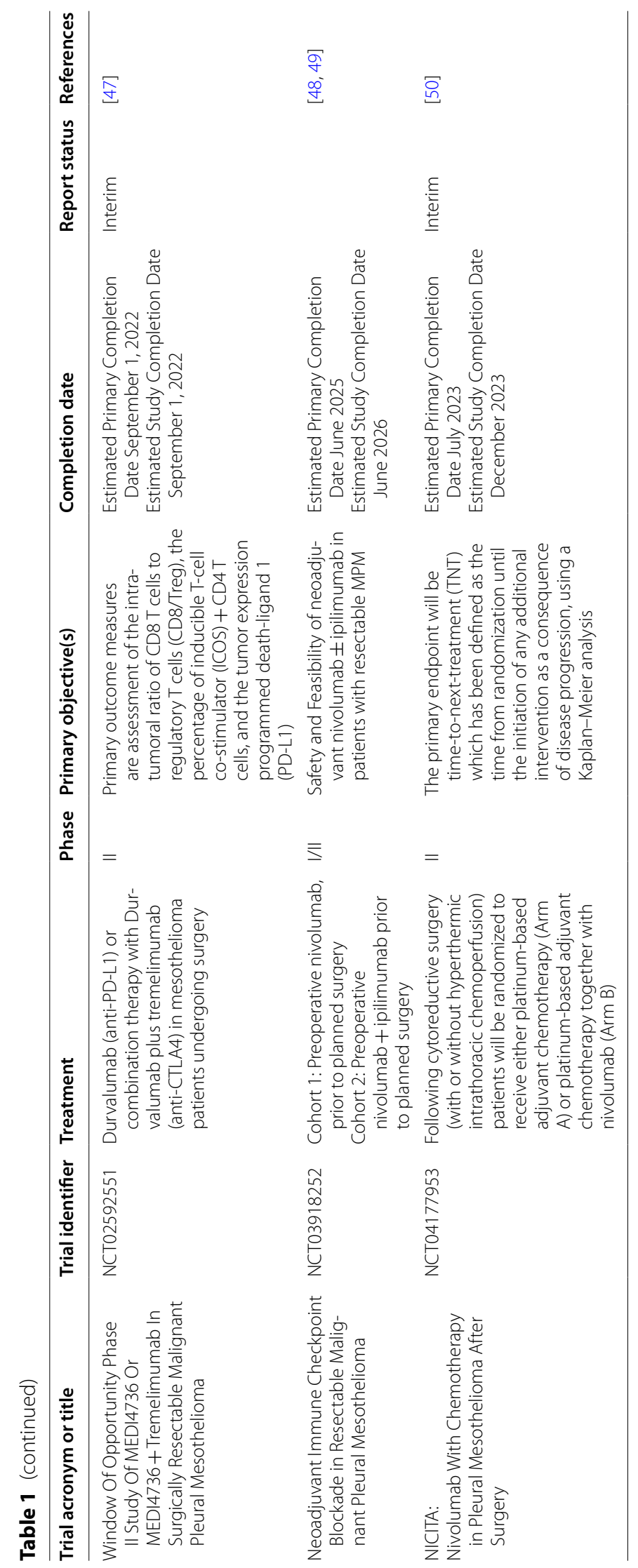




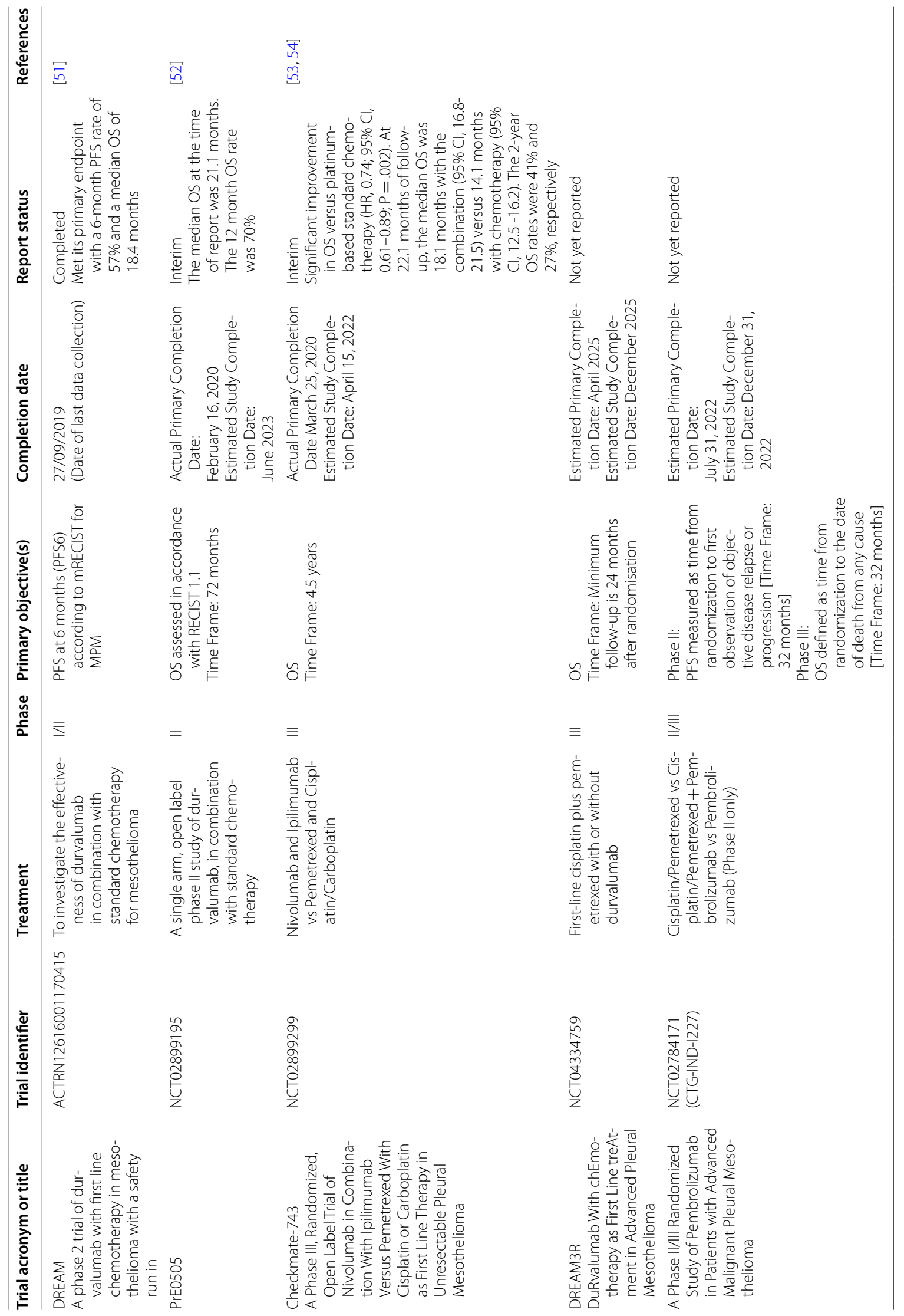




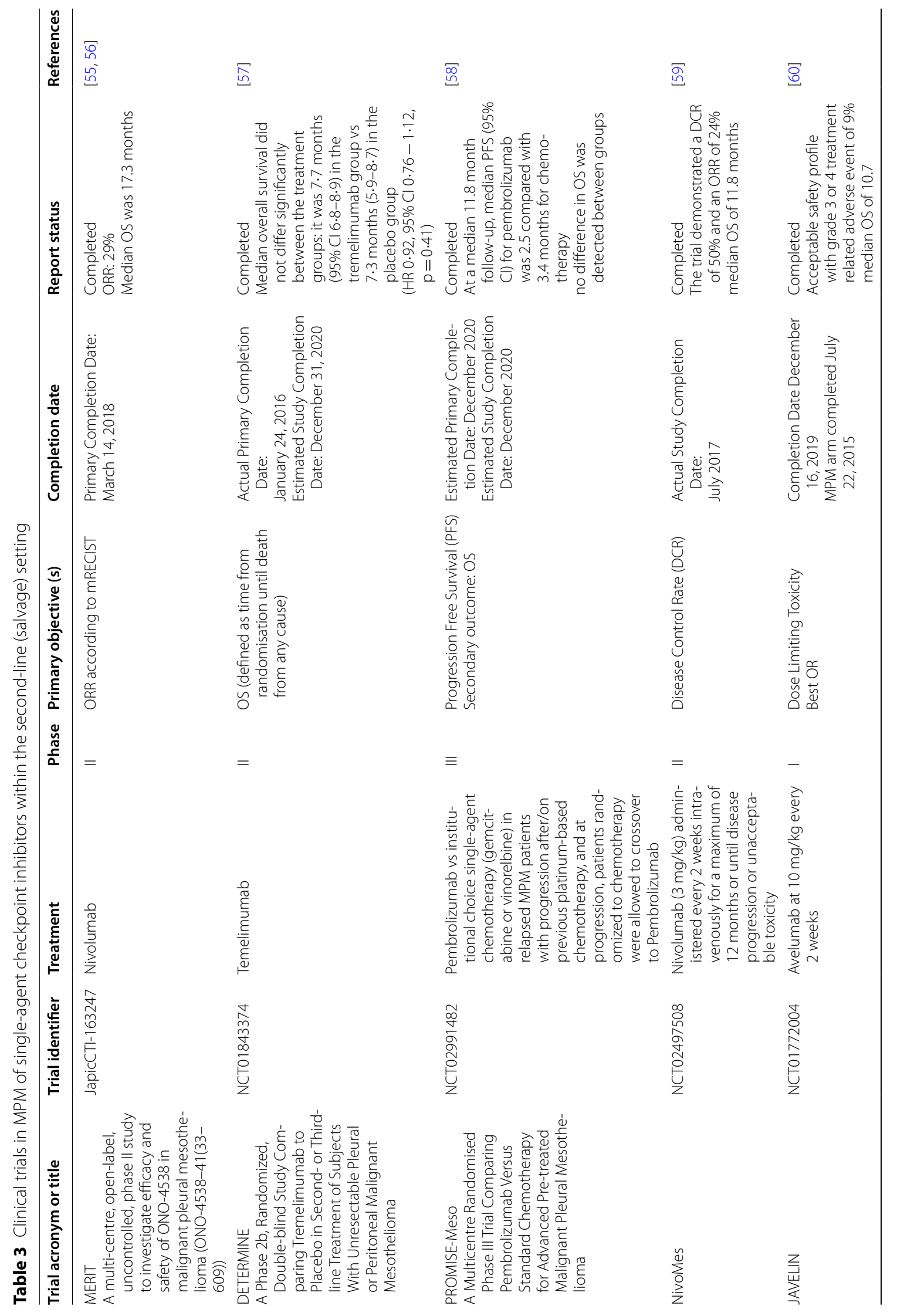




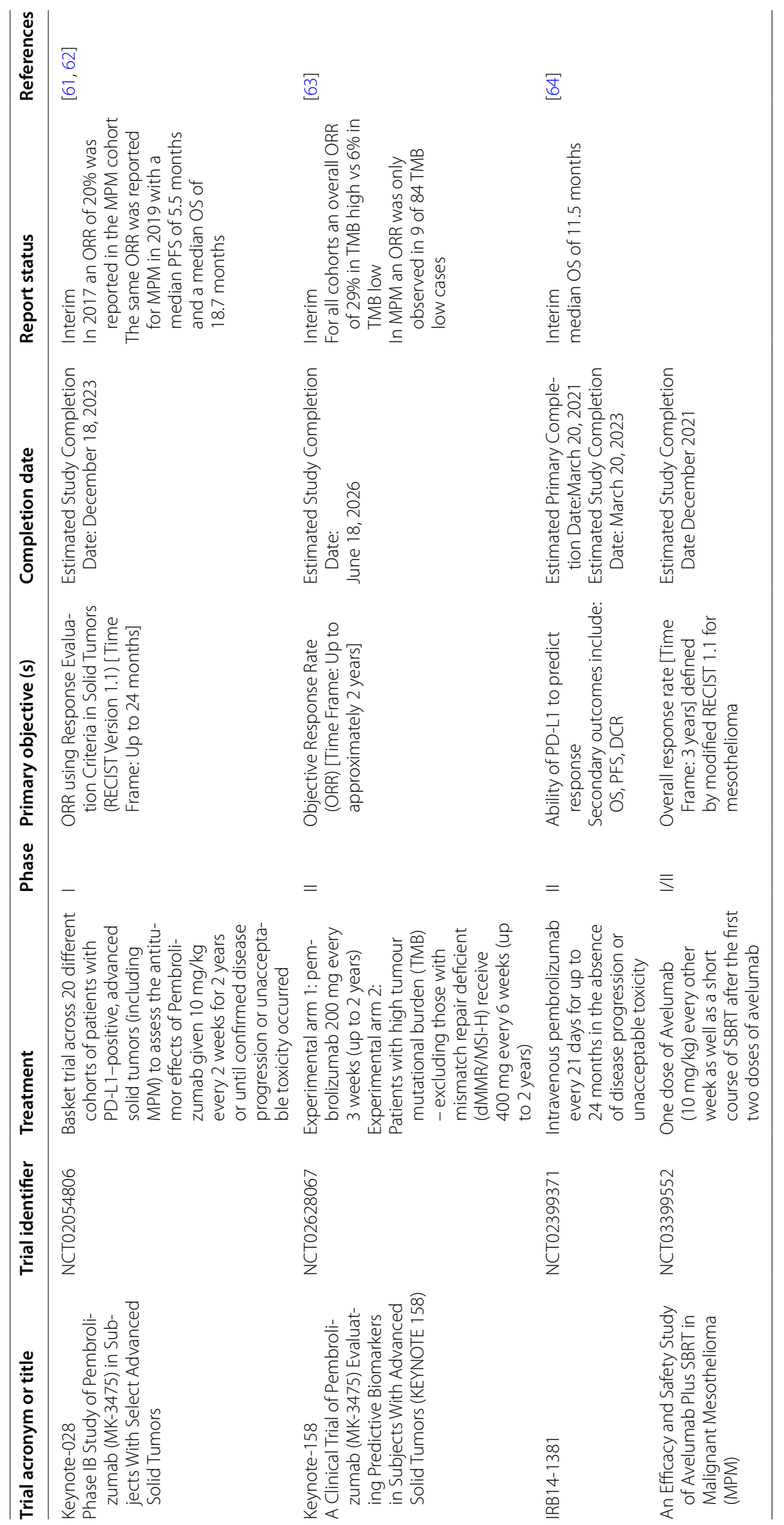




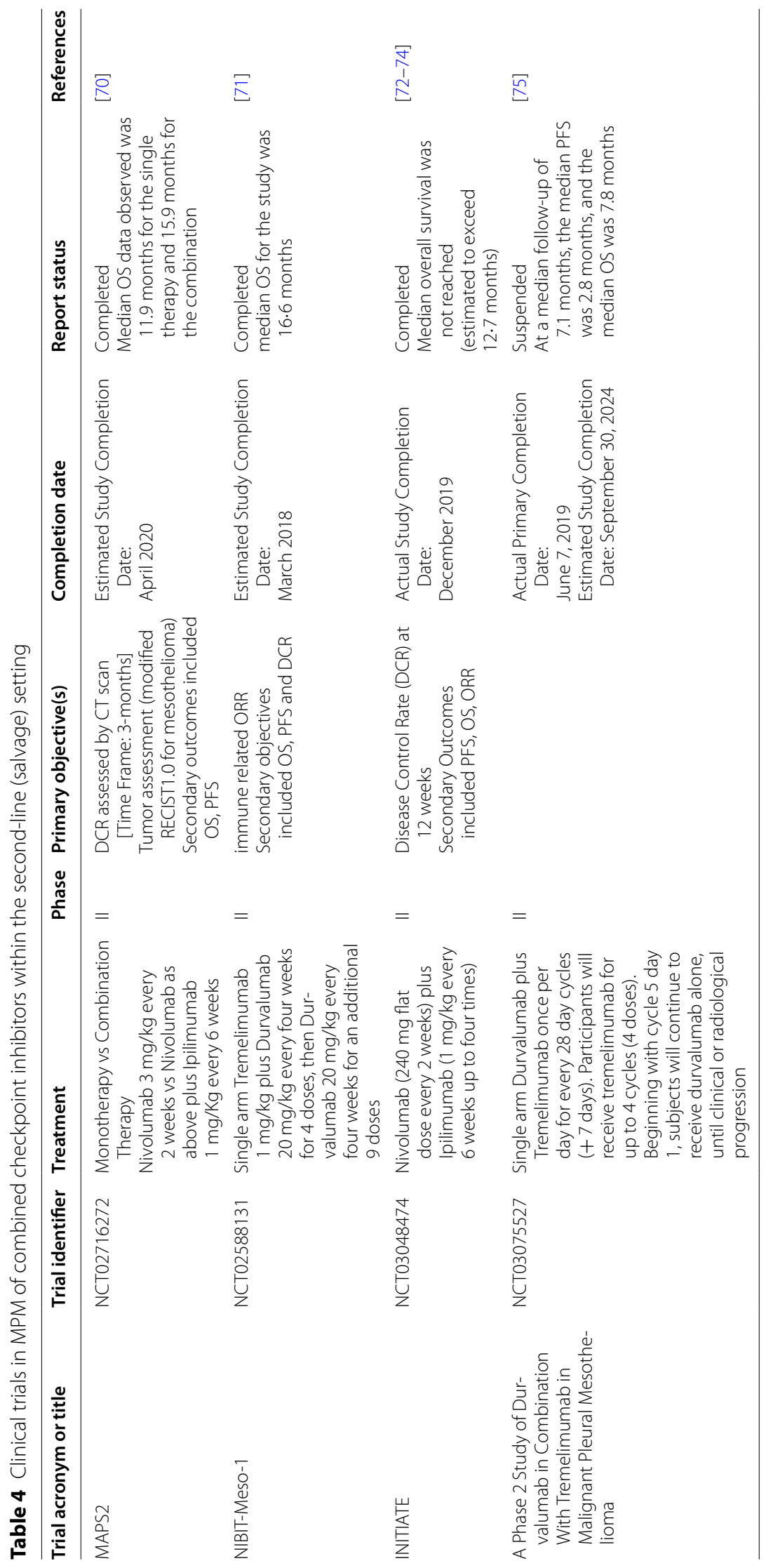


combination therapy induced a profound increase in the proliferation and activation of effector memory $\mathrm{T}$ cells which was not observed in the monotherapy, suggesting a clear benefit for the combination therapy, and therefore this observation warrants a larger Phase III trials of this combination therapy in the salvage setting.

Other trials of combination therapies in the combination setting have not shown as good responses. For example NCT03075527 a single institute trial examining a Durvalumab/ Tremelimumab combination was prematurely terminated as it did not meet its primary endpoint of ORR at interim analysis [75] (Table 4). The results of these trials continue to support the further development of checkpoint inhibitors as both single agents or as combination therapies in MPM.

\section{Are there other checkpoint inhibitor therapy options?}

However, checkpoint inhibitors and anti-tumor immunity are not restricted to just the three candidates (CTLA-4, PD-1, PD-L1) currently described in the previous sections. Many other potential immunotherapy targets have been identified as shown in Table 5, and some potentially actionable candidates are discussed in the following sections.

LAG-3: Lymphocyte activation gene-3 (LAG-3, also known as CD223) is a checkpoint inhibitor, where it acts as an inhibitory co-receptor, playing pivotal roles in autoimmunity, tumor immunity, and anti-infection immunity [79]. A number of agents targeting this receptor are in active clinical development [79]. LAG-3 has been proposed as a candidate checkpoint inhibitor target in MPM [80], and expression of LAG-3 has been identified on immune cell infiltrates isolated from patients with MPM [81]. Most recently a study found that whilst the immune phenotype of pleural fluid cells had no prognostic significance, the presence of PD-1+/LAG-3+/ TIM-3 + CD4 + tumor-infiltrating lymphocytes in pleural biopsy samples correlated with worse overall survival [82]. Intriguingly, analysis of The Cancer Genome Atlas (TCGA) dataset indicates that high mRNA expression of LAG-3 is associated with better OS (Table 5), and a recent analysis suggests that high LAG-3 mRNA expression is a common feature in mesothelioma at both the mRNA and protein level [83, 84].

In a recent report Marcq et al, have shown that in pre-clinical models of MPM, a combination of an antiPD-1/anti-LAG-3 results in delayed tumor growth and survival benefit [85]. Interestingly, a bispecific antibody Tebotelimab (in development by Macrogenics) targets both LAG-3 and PD-1 and is currently in a Phase I dose escalation study (NCT03219268). Preliminary data from this study suggests it has an acceptable safety profile with encouraging early evidence of anti-tumor activity, with one confirmed partial response in a mesothelioma patient [86].

VISTA: V-type immunoglobulin domain-containing suppressor of T cell activation (VISTA) (also known as VSIR or B7H5) is an immune-checkpoint gene which was first reported as having strong expression in epithelioid MPM, above and beyond that seen in other solid cancers, with obvious implications for the immune response to MPM and for its immunotherapy [87]. A subsequent study has confirmed that VISTA expression is higher in epithelioid subtype [88, 89]. High expression of VISTA in epithelioid cancers is associated with a better OS, in both the TCGA dataset (Table 1) and in a separate analysis in the French MESOBANK samples [90]. CA-170 is a small molecule inhibitor of VISTA in development by Curis, and NCT04475523 is an open-label, multicenter doseescalation study of CA-170, assessing the safety and tolerability of this agent in patients with relapsed/refractory solid tumors. This trial had a cohort of $(n=12)$ MPM patients, and the results for this cohort were recently presented, which effectively showed that while CA-170 was well tolerated and showed favorable clinical pharmacokinetics, no partial or complete responses were reported in MPM [91].

B7-H3: B7H3 (also known as CD276) is another candidate checkpoint, whose expression has been observed in mesothelioma [92]. In 2018, it was reported that expression of B7H3 was positive in 41 of 44 mesothelioma samples tested, and of these 39/44 highly expressed B7H3 [93]. The histological subtype of the mesothelioma specimens examined was not provided. A separate study has confirmed that almost all MPM patients across all histological subtypes were positive for B7-H3 (epithelioid - 90.9\%; non-epithelioid - 88.9\%) [94]. In this analysis albeit of a small number of patients $(n=31)$, it was found that the expression level of B7-H3 was significantly higher than that of PD-L1 in the epithelioid type, whereas in non-epithelioid samples, there was no significant difference in the expression levels of PD-L1 and B7-H3 [94]. Analysis of the TCGA dataset demonstrates that high expression of $\mathrm{B} 7 \mathrm{H} 3 \mathrm{mRNA}$ is associated with a worse OS (Table 1).

Several compounds targeting B7-H3 are under active development by companies such as Daichii-Sankyo (DS-7300-a humanized antibody drug (topoisomerase inhibitor) conjugate) or Macrogenics (Enoblituzumab/ MGA271-monoclonal antibody; MGC018-a humanized monoclonal antibody (DNA alkylating agent) conjugate). All are currently in Phase I/II clinical trials. Interim data from the MGC018 trial (NCT03729596) has been presented which indicate that this antibody drug conjugate $(\mathrm{ADC})$ has a manageable safety profile with early evidence of clinical activity [95]. 
Table 5 Known checkpoints examined for expression and survival in MPM

\begin{tabular}{|c|c|c|c|c|}
\hline Gene & Alternative names & Altered expression $^{\mathrm{a}}$ (mRNA) & $O S^{b}(m R N A)$ & Comments \\
\hline CD244 & 2B4 & No & No & \\
\hline TNFRSF9 & $4-1 \mathrm{BB}$ & No & No & \\
\hline ANGPTL7 & CDT6 & No & No & \\
\hline CD80 & B7-1 & No & No & \\
\hline CD86 & B7-2 & No & No & \\
\hline ICOSLG & $\mathrm{B} 7-\mathrm{H} 2$ & No & No & \\
\hline CD276 & B7-H3 & N/A & $\begin{array}{l}\text { Yes } \\
(p=0.039)\end{array}$ & High expression associated with poor OS \\
\hline VTCN1 & $\mathrm{B} 7-\mathrm{H} 4$ & No & No & \\
\hline HHLA2 & $\mathrm{B} 7-\mathrm{H} 5$ & No & No & \\
\hline NCR3LG1 & $\mathrm{B} 7-\mathrm{H} 6$ & N/A & & Not found in UALCAN \\
\hline BTLA & & $\mathrm{N} / \mathrm{A}$ & No & \\
\hline BTN1A1 & BTN & No & No & \\
\hline BTN3A1 & CD277 & $\begin{array}{l}\text { Yes } \\
(p=0.029)\end{array}$ & $\begin{array}{l}\text { Yes } \\
(p=0.0093)\end{array}$ & $\begin{array}{l}\text { Upregulated in MPM } \\
\text { High expression associated with better OS }\end{array}$ \\
\hline ВТN3АЗ & BTF3 & $\begin{array}{l}\text { Yes } \\
(p=0.042)\end{array}$ & $\begin{array}{l}\text { Yes } \\
(p=0.0065)\end{array}$ & $\begin{array}{l}\text { Upregulated in MPM } \\
\text { High expression associated with better OS }\end{array}$ \\
\hline PVR & CD155 & No & $\begin{array}{l}\text { Yes } \\
(p=0.023)\end{array}$ & High expression associated with poor OS \\
\hline CD160 & BY55 & No & No & \\
\hline LY9 & CD229 & No & No & \\
\hline CD28 & Tp44 & No & No & \\
\hline TNFRSF8 & CD30 & No & No & \\
\hline CD40 & TNFRSF5 & No & No & \\
\hline CD47 & MER6, IAP & $\begin{array}{l}\text { Yes } \\
(p=0.012)\end{array}$ & No & Upregulated in MPM \\
\hline CD48 & BLAST1 & No & No & \\
\hline CD84 & SLAMF5 & No & $\begin{array}{l}\text { Yes } \\
(p=0.042)\end{array}$ & High expression associated with poor OS \\
\hline CD96 & TACTILE & No & No & \\
\hline CTLA-4 & CD152 & No & No & \\
\hline CD226 & DNAM-1 & No & No & \\
\hline LGALS9 & Galectin-9 & No & No & \\
\hline TNFRSF18 & GITR & N/A & No & \\
\hline TNFRSF14 & HVEM & No & $\begin{array}{l}\text { Yes } \\
(p=0.019)\end{array}$ & High expression associated with better OS \\
\hline TIM3 & HAVCR2 & No & No & \\
\hline $\mathrm{ICOS}$ & AILIM & No & No & \\
\hline LAG3 & CD223 & $\begin{array}{l}\text { Yes } \\
(p=0.011)\end{array}$ & $\begin{array}{l}\text { Yes } \\
(p=0.021)\end{array}$ & $\begin{array}{l}\text { Upregulated in MPM } \\
\text { High expression associated with better OS }\end{array}$ \\
\hline LAIR-1 & & No & No & \\
\hline LAIR-2 & CD306 & No & No & \\
\hline LILRA2 & LIR7, CD85H & No & $\begin{array}{l}\text { Yes } \\
(p=0.038)\end{array}$ & High expression associated with better OS \\
\hline LILRA3 & LIR4, CD85E & No & No & \\
\hline LILRA5 & LIR9, CD85F & No & No & \\
\hline LILRB1 & LIR1, CD85 & No & No & \\
\hline LILRB2 & LIR2, CD85D & No & No & \\
\hline LILRB3 & LIR3, CD85A & No & No & \\
\hline LILRB4 & LIR5, CD85K & No & No & \\
\hline LILRB5 & LIR8, CD85C & No & No & \\
\hline
\end{tabular}


Table 5 (continued)

\begin{tabular}{|c|c|c|c|c|}
\hline Gene & Alternative names & Altered expression ${ }^{a}$ (mRNA) & $O S^{b}(m R N A)$ & Comments \\
\hline Nectin-1 & PVRL1 & No & $\begin{array}{l}\text { Yes } \\
(p=0.0042)\end{array}$ & High expression associated with poor OS \\
\hline Nectin-2 & PVRL2 & No & No & \\
\hline Nectin-3 & PVRL3 & $\begin{array}{l}\text { Yes } \\
(p=0.012)\end{array}$ & $\begin{array}{l}\text { Yes } \\
(p=0.024)\end{array}$ & $\begin{array}{l}\text { Upregulated in MPM } \\
\text { High expression associated with poor OS }\end{array}$ \\
\hline NCR3 & NKp30 & No & No & \\
\hline SLAMF6 & NTB-A & N/A & No & \\
\hline OX40 & TNFRSF4 & No & No & \\
\hline OX40L & TNFSF4 & $\begin{array}{l}\text { Yes } \\
(p=0.047)\end{array}$ & $\begin{array}{l}\text { Yes } \\
(p=0.00018)\end{array}$ & High expression associated with poor OS \\
\hline PD1 & CD279 & No & No & \\
\hline PD-L1 & CD274 & N/A & No & \\
\hline PD-L2 & B7DC & No & No & \\
\hline PVRIG & CD112R & No & No & \\
\hline SIRPA & PTPNS1 & No & $\begin{array}{l}\text { Yes } \\
(p=0.0091)\end{array}$ & High expression associated with better OS \\
\hline SIRPG & SIRP gamma & No & No & \\
\hline SIRPB1 & SIRP-beta 1 & $\begin{array}{l}\text { Yes } \\
\left(p=7.92 \times 10^{-7}\right)\end{array}$ & No & Upregulated in MPM \\
\hline SIRPB2 & & N/A & No & \\
\hline SLAMF1 & CD150 & No & No & \\
\hline SLAMF7 & CD319 & No & No & \\
\hline TIGIT & & N/A & No & \\
\hline VISTA & VSIR, C10ORF54 & $\mathrm{N} / \mathrm{A}$ & $\begin{array}{l}\text { Yes } \\
(p=0.00093)\end{array}$ & High expression associated with better OS \\
\hline VSIG3 & IGSF11 & N/A & No & Ligand of VISTA \\
\hline VSIG4 & CRIG & No & No & \\
\hline
\end{tabular}

Bold value represents significance at $\mathrm{p}<0.05$

${ }^{\text {a }}$ Assessed using oncomine analysis [76] of the Gordon MPM dataset (normal pleura versus malignant) [77]

${ }^{\mathrm{b}}$ Assessed using UALCAN [78]

TIM3: The T-cell inhibitory receptor Tim3 (T-cell immunoglobulin and mucin-domain containing-3) is a heavily investigated immune- checkpoint [96], and demonstrating significant pre-clinical activity [97, 98]. Tim3 expression has been examined in MPM, and its expression is found on both tumor cells and immune cells [81, 99], and double-positive PD-1 + /TIM-3 + CD8 + T cells are more commonly found in PD-L1-positive tumors [99]. Whilst expression of this receptor does not have any prognostic value (Table 1) in the MPM TCGA dataset, its expression suggests that it may be a potential new target in mesothelioma $[85,100]$.

TIGIT: The role of inhibitory repressors (IRs) on tumor infiltrating lymphocytes (TILs) is generally associated with T-cell exhaustion. In such a situation, when exposed to chronic tumor antigens, $T$ cells become dysfunctional/exhausted and upregulate various checkpoint inhibitory receptors (IRs) that limit their survival and function [101]. In a recent analysis of TILs isolated from patients with MPM [102], it was observed that the levels of TIGIT were significantly greater on TILs isolated from MPM compared with those isolated from tumor free lungs (TFLs), with high levels of TIGIT on $~ 60 \%$ of CD8 + T-cells [102]. Functionally, the expression of TIGIT was associated with TIL hypofunction [102], suggesting that an anti-TIGIT therapy may have potential for therapeutic use in mesothelioma [102], and a number of clinical trials and anti-TIGIT therapies are in progress [103].

BTN3A1/ BTN3A3: Butyrophilin subfamily 3 (BTN3) genes are emerging as checkpoints critical to the regulation of immune responses for specific $\gamma \delta \mathrm{T}$ cell (VY9V82T) subsets which can exert anti-tumoral effects [104]. Two of these BTN3A1 (CD277) and BTN3A3 (BTF3) are upregulated in MPM and high expression is associated with MPM OS (Table 5). Vy $9 \mathrm{~V} \delta 2 \mathrm{~T}$ cell infiltration into tumor tissues is associated with a positive prognosis across multiple cancers [105], which makes the BTN3A subfamily an interesting target for enhancing anti-tumor immunity. Several companies have developed 
agents targeting butyrophilins. One candidate is a humanized anti-Butyrophilin 3A (BTN3A) monoclonal antibody (ICT01) developed by ImCheck Therapeutics and which is currently in a Phase I/IIA (NCT04243499) first-in-human, open-label clinical trial to characterize the safety, tolerability and activity of as monotherapy and in combination with Pembrolizumab in patients with advanced, relapsed/refractory cancer, including both solid tumors and hematologic cancers. Preliminary data from the first dose cohort of patients with solid tumors were recently presented and show a favorable safety profile with robust activation and migration of $\gamma 9 \delta 2 \mathrm{~T}$ cells at doses as low as $1 \mu \mathrm{g} / \mathrm{kg}$ [106].

OX40/OX40L: These are members of the TNF receptor superfamily (TNFRSF), and are key co-stimulators of $\mathrm{T}$ cells during infection, and there has been an increasing interest in harnessing these receptors to augment tumor immunity. OX40 (TNFRSF4) and OX40L (TNFSF4) have been implicated in mesothelioma. In a recent study of an animal model of mesothelioma, tumor resident regulatory $\mathrm{T}$-cells were shown to co-express high levels of CTLA-4 and OX40 on a large proportion of cells. Individually targeting OX40 generated an effective response against tumor development, and was found to be synergistic with anti-CTLA4 agents [107]. Whilst there appears to be little information as regards OX40L in mesothelioma, analysis suggests that OX40L is overexpressed in MPM and high expression is associated with poorer OS (Table 1). At present a Phase I clinical trial (NCT03894618) of SL-279252 (PD1-Fc-OX40L) is assessing the safety, tolerability, pharmacokinetics, antitumor activity and pharmacodynamic effects of this bifunctional fusion protein [108] in patients with advanced solid tumors or lymphomas. The trial is expected to complete in April, 2022.

Other candidate checkpoints which could be therapeutically targeted include PVR (CD155), CD47 (MER6, IAP), CD84 (SLAMF5), TNFRSF14 (HVEM), and various members of the nectins (Table 5). Clearly, as our knowledge of checkpoint inhibitor therapy improves, the wealth of candidate targets and agents currently under investigation coupled with emerging data from patients with MPM suggest that further investigations of combination immune checkpoint inhibitor therapy are warranted.

\section{Beyond checkpoint inhibitors}

\section{Oncolytic therapy?}

While early studies of interferon or GM-CSF based MPM therapy based on infusions proved disappointing, new therapeutic strategies which involve oncolytic virus mediated expression of these agents may have more clinical activity and benefit.
Oncolytic adenovirus overexpression of IFN: Several Phase I trials involving intra-pleural infusion of adenoviral mediated interferon therapy have been attempted in recent years [109-111]. In the most recent of these (ClinicalTrials.gov NCT01119664), 40 patients received two intra-pleural doses of a replication-defective adenoviral vector containing the human IFN $2 \mathrm{~b}$ gene (Ad. IFN) concomitant with a 14-day course of celecoxib followed by chemotherapy (either first line with pemetrexed, or second-line with pemetrexed or gemcitabine. whilst patients in the first-line cohort had median OS of 12.5 months, in second-line settings the median OS was 21.5 months with $32 \%$ of patients alive after 2 years [109]. A new Phase III study-(INFINITE-NCT03710876) is currently recruiting for a trial involving intra-pleural administration of TR002 an adenovirus-delivered Interferon Alpha-2b (rAd-IFN) and examining its efficacy and safety in combination with celecoxib and gemcitabine in patients with mesothelioma.

Oncolytic measles virus overexpression of IFN: On a separate note, in 2015 defects within the interferon typeI response were found to render MPM cells sensitive to oncolytic measles virus [112], and a follow up study found that the defects in IFN-I responses that renders them sensitive to oncolytic activity induced by exposure to the measles virus were most frequently homozygous deletions of all the 14 IFN-I genes (IFN- $\alpha$ and IFN- $\beta$ ) [113]. These results suggest that the interferon pathway continues to be potentially important immunotherapy target in MPM.

Intriguingly, a recent report indicates that IFN- $\gamma$ treatment of mesothelioma cells results in both the upregulation of membranous PD-L1 [114], which suggest that interferon therapy, could be combined with anti-PDL1 checkpoint inhibitors for the treatment of MPM.

Oncolytic adenovirus overexpression of GM-CSF: ONCOS-102 is an immune-priming GM-CSF coding oncolytic adenovirus in development by Targovax. The safety, immune and clinical results of an open-label Phase I/II clinical trial of ONCOS-102 in combination with pemetrexed/cisplatin (NCT02879669) for 1st and 2nd line unresectable MPM have just been reported, and indicate that the immune priming function of ONCOS102 was both safe and had robust immune activation, with increased T-cell infiltration [115]. Moreover upregulation of PD-L1 was noted, which could potentially allow for future combinations with checkpoint inhibitors [115]. Currently, Targovax has been granted a European Patent for combining this oncolytic virus with checkpoint inhibitors (European Patent no 3293201) [116], and has further announced a collaboration with Merck to evaluate ONCOS-102 with Pembrolizumab in MPM [117]. The envisaged trial will be a randomized phase II of up 
to 100 patients comparing this investigational triple combination against Pembrolizumab and SOC, with multiple centers in both the USA and EU participating, and the aim will be to start enrolling patients into the trial within twelve months. Moving forwards it will be interesting to see the results of any clinical trials combining ONCOS102 and checkpoint inhibitors.

\section{CAR-T based approaches}

Chimeric antigen receptors (CARs) therapy functions by coupling the Human leukocyte antigen (HLA)-independent binding of a cell surface target to the delivery of a tailored T-cell activating signal by recognizing and binding to specific tumor-associated antigens $[118,119]$. The potential to use CAR-T therapy in mesothelioma has been explored fairly extensively, and pre-clinical models using various targets including mesothelin (MSLN) [120, 121], Fibroblast activation protein (FAP) [122], Met Proto-oncogene (cMET) [123], pan-ErbB [124] and others have been extensively tested $[125,126]$.

Various clinical trials of CAR-T based approaches in MPM have been conducted and were recently summarized by us and others $[47,118,119,127]$.

One factor which may currently limit the use of CAR-T strategies in solid tumors could be the issue of T-Cell exhaustion [128]. However, recent studies suggest that checkpoint inhibitors may be a mechanism for improving the potency of CAR-T cell therapies in this regard [129-131], and other approaches such as co-stimulation induction and cytokine based approaches may also have merit [128].

Dendritic cell (DC) therapy is a cell based vaccination approach used to initiate an anti-tumor immune response [127]. In mesothelioma initial approaches used autologous tumor lysate loaded DCs, and have showed excellent long lasting clinical responses with survival up to 66 months post treatment [132-136]. While greatly encouraging, the main disadvantage of this approach remains that it is time-consuming and may not often generate sufficient amounts of the required quality for DC therapy. Allogenic tumor lysates have the possibility to circumvent this drawback [137], and a Phase I clinical trial MesoCancerVa (NCT02395679) has recently completed. In this trial, no dose-limiting toxicities were established and radiographic responses were observed. The median PFS was 8.8 months and median OS was not reached at a median follow-up of 22.8 months [137]. In a follow up analysis of the peripheral blood $\mathrm{T}$ cell receptor $\beta$ (TCR $\beta$ ) chain repertoire of nine MPM patients before and 5 weeks after the start of dendritic cell (DC)-based immunotherapy, it was found that clinical responses to DC-mediated immunotherapy was dependent on both the pre-existing TCR $\beta$ repertoire of total $\mathrm{CD} 3+\mathrm{T}$ cells and on therapy-induced changes, in particular expanding $\mathrm{PD} 1+\mathrm{CD} 8+\mathrm{T}$ cell clones, and therefore TCR $\beta$ repertoire profiling could potentially allow for the selection of MPM patients that might benefit from DC-based immunotherapy [138].

These promising results have led to the establishment of the Phase II/III DENIM trial (NCT03610360) which aims to recruit $n=230$ patients to examine the OS in patients treated with DCs loaded with this allogeneic tumor cell lysate as maintenance treatment after chemotherapy [139]. This trial is estimated to complete in January, 2021, and the results will be eagerly awaited.

\section{Outstanding issues and other therapeutic considerations}

Clearly immunotherapy will in the future play important roles in the management of this cancer. As we continue to develop our understanding and knowledge of these exciting therapeutic options and avenues of approach, additional issues and possibilities arise summarized in Table 6, and are discussed in more detail in the following sections.

Table 6 Additional areas of interest within mesothelioma immunotherapy

\begin{tabular}{ll}
\hline Outstanding areas of interest for immunotherapy in MPM \\
\hline 1 & Can we combine Tumor-Treating Fields (TTF) with checkpoint inhibitors? \\
2 & How can we best stratify patients to checkpoint inhibitors? \\
3 & Is there any utility for the use of PD-L1 expression as a biomarker to direct therapy? \\
4 & Can we epigenetically prime MPM for checkpoint inhibitor therapy? \\
6 & Can we use BAP1 status in immunotherapy of MPM? \\
7 & Would targeting Toll Like Receptors (TLRs) along with checkpoint inhibitors prove beneficial? \\
8 & What is the best way to monitor response to checkpoint inhibitors? \\
\hline
\end{tabular}


Tumor-treating fields and checkpoint inhibitors

Developed by Novocure, the NovoTTF ${ }^{\mathrm{TM}}-100 \mathrm{~L}$ System is a device which uses alternating electric fields at specific frequencies and intensities (called Tumor Treating Fields or TTF) to selectively disrupt mitosis in cancerous cells [140]. This technology has received FDA approval for use in MPM [141], though concerns exist as to whether potential inherent biases and lack of sufficient controls can allow for a true interpretation of the therapeutic value of this system in MPM [141-144].

Novocure has recently initiated Phase III clinical trials (e.g. NCT02973789) of its platform in combination with immune checkpoint inhibitors in NSCLC [145]. If these clinical trials show efficacy it will interesting to see if similar clinical trials of the NovoTTF ${ }^{\mathrm{TM}}-100 \mathrm{~L}$ System combined with checkpoint inhibitors will be conducted with MPM moving forwards.

\section{Patient stratification: Is there a role for tumor mutational burden in predicting response to immunotherapy?}

Tumor mutational burden (TMB) is emerging as a strong predictor for identifying cohorts of patients who may respond to checkpoint inhibitor based therapy [146]. Theoretically, a higher TMB should therefore increase the likelihood for tumor neo-antigen production and as such the probability for immune recognition and tumor cell killing [147]. Even though MPM is considered to have a low TMB $[48,148,149]$, TMB has been assessed is some available studies of checkpoint inhibitors.

Keynote-028-Expanding on a more detailed analysis of the entire trial cohort $(n=475)$ it was found that T-cell-inflamed gene expression profiles (GEP), PD-L1 expression and/or tumor mutational burden was associated with a higher likelihood of response to therapy. Within this analysis of the $\mathrm{n}=25$ mesothelioma patients $\mathrm{n}=19$ had GEP; $\mathrm{n}=12$ had PD-L1 positivity and $\mathrm{n}=9$ had TMB data available [61]. However, no subgroup analysis was available for the mesothelioma cohort alone.

In an analysis of the Keynote-158 study with a prespecified cutpoint of at least 10 mutations per megabase as TMB-high, 9/84 MPM patients who were assessed as being TMB-low had an ORR [63], although in terms of PFS and OS TMB-high status with Pembrolizumab treatment was not significant for the overall population [150]. In a single case study, an MPM patient who derived a prolonged response to a checkpoint inhibitor (45 months to 52 cycles of Pembrolizumab) was also assessed for TMB. The baseline biopsy was found to have 0.92 somatic mutations per megabase, while the relapse biopsy had 0.26 [151]. The issue of TMB therefore remains to be resolved for its potential utility in predicting or stratifying MPM patients to checkpoint inhibitor based immunotherapy.

\section{Is there any utility for the use of PD-L1 expression} as a biomarker to predict response?

The role of PD-L1 expression as a biomarker to predict outcome in MPM is still an ongoing issue that has yet to be resolved. If one considers the results of Checkmate-743, PD-L1 status does not predict for OS benefit as similar survival was seen in the subgroups with less than $1 \%$ vs $1 \%$ or greater PD-L1 status [53]. Similar results have been observed in other clinical trials [58, 59, 71]. The results of the MERIT trial found that differences in OS and PFS favored positive PDL-1 expression (although not-significant) [55]. What is emerging from these studies is that expression of PD-L1 is associated with higher ORR $[60,69,70,72,152]$, and in analysis of the Dutch expanded access program, long survival for patients with partial responses suggested a clinical benefit that is correlated with ORR [69]. Moreover, expression of PD-L1 and non-epithelioid histology is associated with higher ORR $[55,69]$

One feature that emerged from Checkmate-743 was that patients who had tumor PD-L1 expression of less than $1 \%$ had better survival with chemotherapy which suggests that absence of PD-L1 might be indicative for chemotherapy based regimens. Support for this comes from a recent analysis of the immune microenvironment in MPM which identified that chemotherapy treated patients deriving the best OS were PD-L1 negative and had a higher percentage of stromal CD8+lymphocytes [153, 154]. Likewise, the Dutch nivolumab EAP study also found that patients no PD-L1 expression had very poor responses to Nivolumab with significantly worse ORR and mOS $[68,69]$.

Other interesting developments as regards PD-L1 expression as a candidate biomarker are emerging from the CONFIRM trial which found that PD-L1 expression had no bearing on OS [67].

As such PD-L1 remains a contentious biomarker in this sphere, and a significant number of patients exist who whilst being PD-L1 negative, demonstrate ORRs to checkpoint inhibitors. The challenge will be to identify new markers or ways to identify such patients, perhaps using transcriptomic or other approaches [53, 154-157].

\section{Is there a role for epigenetic priming in the use of checkpoint inhibitor therapy for MPM?}

Epigenetic priming is emerging as a mechanism to potentially prime solid tumors for enhanced targeting of immune checkpoint inhibitors via the induction or upregulation of PD-L1. It is now well established that epigenetic targeting agents such as decitabine (a DNA methyltransferase inhibitor) can induce or upregulate PD-L1 expression [158, 159]. In this regard a clinical trial (NCT03233724) designed primarily for NSCLC 
Table 7 Additional clinical trials in MPM utilizing checkpoint inhibitors

\begin{tabular}{|c|c|c|c|c|c|c|c|}
\hline Trial acronym or title & Trial identifier & Treatment & Phase & Primary objective (s) & Completion date & Report status & References \\
\hline $\begin{array}{l}\text { Phase I/II Evaluation } \\
\text { of Oral Decitabine/ } \\
\text { Tetrahydrouridine as } \\
\text { Epigenetic Priming } \\
\text { for Pembrolizumab } \\
\text { Immune Check- } \\
\text { point Blockade in } \\
\text { Inoperable Locally } \\
\text { Advanced or Meta- } \\
\text { static Non-Small Cell } \\
\text { Lung Cancers, and } \\
\text { Esophageal Carci- } \\
\text { nomas, or Pleural } \\
\text { Mesotheliomas }\end{array}$ & NCT03233724 & $\begin{array}{l}\text { Experimental: } 1 \\
\text { (Dose Escalation) } \\
\text { Decitabine (DAC) } \\
\text {-Tetrahydrouridine } \\
\text { (THU) + pembroli- } \\
\text { zumab at escalating } \\
\text { doses } \\
\text { Experimental: } 2 \\
\text { Dose Expansion } \\
\text { DAC-THU + pembroli- } \\
\text { zumab at the dose } \\
\text { established in Arm } 1\end{array}$ & $|/| \mid$ & $\begin{array}{l}\text { Maximum Tolerated } \\
\text { Dose (MTD) } \\
\text { ORR - to determine if } \\
\text { the combination is } \\
\text { associated with an } \\
\text { ORR which exceeds } \\
\text { that of Pembroli- } \\
\text { zumab alone in } \\
\text { patients who have } \\
\text { PD-L1 expression } \\
\text { of at least } 50 \% \text { and } \\
\text { those who do not }\end{array}$ & $\begin{array}{l}\text { Estimated Study } \\
\text { Completion } \\
\text { Date: December } \\
\text { 31, } 2026\end{array}$ & $\begin{array}{l}\text { Running no } \\
\text { interim results } \\
\text { as yet }\end{array}$ & \\
\hline $\begin{array}{l}\text { ORIGIN } \\
\text { Overcoming Resist- } \\
\text { ance to Immuno- } \\
\text { therapy Combining } \\
\text { Gemcitabine With } \\
\text { Atezolizumab in } \\
\text { Advanced NSCLC } \\
\text { and Mesothelioma } \\
\text { Progressing Under } \\
\text { Immune-checkpoint } \\
\text { Inhibitors or Gemcit- } \\
\text { abine. A Multicenter, } \\
\text { Single-arm, Open } \\
\text { Label Phase II Trial } \\
\text { With Two Cohorts }\end{array}$ & NCT04480372 & $\begin{array}{l}\text { Cohort 1. NSCLC } \\
\text { Cohort 2. Inoperable } \\
\text { MPM } \\
\text { gemcitabine } 1000 \text { mg/ } \\
\text { m2 on day } 1 \text { and } \\
\text { day } 8 \text { of each cycle } \\
\text { (every } 3 \text { weeks) and } \\
\text { with atezolizumab } \\
1200 \text { mg on day } 1 \\
\text { of each cycle (every } \\
3 \text { weeks) }\end{array}$ & $\|$ & ORR & $\begin{array}{l}\text { Estimated Primary } \\
\text { Completion } \\
\text { Date: } \\
\text { April } 2025 \\
\text { Estimated Study } \\
\text { Completion } \\
\text { Date: December } \\
2025\end{array}$ & Not yet recruiting & \\
\hline
\end{tabular}

(but includes MPM) (Table 7), aims to assess if epigenetic targeting with Decitabine can prime solid tumors for enhanced targeting of immune checkpoint inhibitors (in this instance Pembrolizumab) [160].

Other epigenetic targeting agents such as histone deacetylase inhibitors (HDACi) are also well established as candidate agents with the capacity to induce PD-L1 in cancer cells [161-164]. However, in MPM cell lines HDACi by themselves had modest effects on PD-L1, but when combined with decitabine, higher induction of this checkpoint inhibitor were observed [165].

\section{Can a patients BAP1 status inform therapy decisions?}

Given the potential sensitivity of BAP1 mutated MPM to Enhancer of Zeste 2 (EZH2) inhibitors [166], is there an opportunity to combine EZH2 inhibitors with checkpoint inhibitors? In a non-mesothelioma setting, a patient with SMARCB1-deleted, metastatic, poorly differentiated chordoma was treated with Tazemetostat (EZH2 inhibitor), and had a significant increase in intratumoral and stromal infiltration by immune cells expressing checkpoint regulators PD-1 and LAG-3 [167]. In this regard, preliminary data from the EZH-203 (NCT02860286) trial of Tazemetostat in MPM had a 12 week DCR of $47 \%$ $(n=35)$, with mostly stable disease with no complete responses and only 2 partial responses [168]. Given the observation that Tazemetostat results in enhanced infiltration of immune cells it may be possible to conceive of a strategy which could include Tazemetostat/anti-PD1 in BAP1 mutant patients. In this regard, a recent study has shown that while macrophages can be directly cytotoxic for mesothelioma cells, inhibition of EZH2 reduced that activity because it induced PD-1 overexpression. A combination of PD-1 blockade and EZH2 inhibition restores macrophage cytotoxicity [169]; and suggests that combination therapy with EZH2 inhibitors plus checkpoint inhibitors may have potential for clinical efficacy in MPM.

For those patients with wild-type BAP1, there may be a possibility to combine gemcitabine with immunotherapy. Initial pre-clinical studies suggest that it did not change the expression of PD-L1 on human mesothelioma cell lines in vitro [170]. Additional evidence now suggests that wild-type (WT) BAP1 positivity may be a factor in the sensitivity of MPM to gemcitabine [171, 172]. Moreover, a recent study using PET demonstrated that gemcitabine based therapy in a murine colon cancer model strongly induced PD-L1 Expression [173]. Furthermore, a synergistic effect for gemcitabine combined with anti-PD1 was observed in pre-clinical models of mesothelioma, and similar responses were seen in two patients who were resistant to gemcitabine or anti-PD-1 (Pembrolizumab) 
as monotherapy, but who achieved observable clinical responses following combination therapy [170], and has led to the ORIGIN trial (Table 7), which will examine if a Gemcitabine/Atezolizumab combination can overcome resistance in either advanced NSCLC or Mesothelioma patients progressing under immune-checkpoint inhibitors or gemcitabine. Intriguingly, gemcitabine has been shown by us to act as a DNA methyltransferase inhibitor, reactivating silenced genes in mesothelioma cells [174], and as such the observed responses to gemcitabine on PD-L1 expression changes may reflect an epigenetic priming event, although functional studies will be required to delineate this.

\section{Can combined targeting of TLRs and checkpoint inhibitors improve responses to immunotherapy?}

Toll-like receptors (TLRs) are expressed on many innate immune system cells and play a role in maturation of dendritic cells and priming of cytotoxic $\mathrm{T}$ lymphocytes [175]. A subset of TLRs has been shown to stimulate antitumor responses, and agonists to these receptors are being investigated in clinical trials $[175,176]$. Several studies have linked TLR3, TLR7 and TLR9 as potentially targetable in MPM [177-179], which could conceivably be trialed in combination with checkpoint inhibitors [180]. It is interesting to note that NCT02668770 is a clinical trial of ipilimumab and MGN1703 (a TLR Agonist) currently running in patients with advanced solid malignancies. Whether any mesothelioma patients are in this trial is unknown.

\section{What is the best way to monitor immunotherapy response?}

Hyper-progression, an accelerated growth or progression of a cancer after treatment is initiated, has been observed for a subset of patients undergoing checkpoint inhibitor therapy [181], and can emerge either during therapy, or can emerge post-therapy [182, 183]. This further complicated by the issue of pseudo-progression where patients obtain an objective response following an initial progression with immunotherapy [184] The estimated occurrence of hyper-progression is estimated at 4 to $29 \%$, while that of pseudo-progression ranges from 0 to $15 \%$ [184]. Whilst there is little evidence that hyperprogression occurs during treatments of mesothelioma, two patients have reported as showing pseudo-progression under treatment with Pembrolizumab, within the first 15-30 weeks of therapy followed by responses [185]. Additionally in the DREAM trial, two patients (4\%) were also observed to undergo pseudo-progression in response to treatment with Durvalumab [51].

In a recent editorial on this topic key issues remain such as: why it occurs; is it simply a lead-time bias phenomenon; does it have a strong biological basis such as clonal selection; can we identify and predict those in whom it will occur; and if be stopped by additional therapies [186]. As more and more clinical trials of immunotherapies complete in mesothelioma, vigilance will be required to assess if hyper-progression does occur in MPM while undergoing treatment with immunotherapy.

Some efforts have been made to differentiate pseudoprogression from progression and hyper-progression, such as radiological responses DNA [184]. As PET/CT imaging has been used for the prediction of survival in response to Pembrolizumab in mesothelioma [187], and may be useful to incorporate into immunotherapy based regimens for the treatment of mesothelioma. Other methods that have been explored in other cancer types have involved analyses circulating-tumor DNA or cell-free DNA to assess response to immunotherapy, but larger prospective cohort studies will be required to confirm their potential use [184]. Pathologic scoring of responses to immunotherapy has also been explored [188, 189], but may have limited utility in distinguishing between pseudo-, hyper- and progression in MPM. Clearly, new methods or modalities to monitor immunotherapy response will be required moving forwards.

\section{Is the cost prohibitive for the use of checkpoint inhibitors in the second-line/salvage setting?}

The combined cost for Ipilimumab/Nivolumab in the USA has been estimated approximately $\$ 153,800$ for four cycles, while that of Nivolumab alone would be of the order of $\$ 87,000$ [190]. One of the most commonly used chemotherapies in the treatment of MPM in the secondline or salvage setting is vinorelbine [191], which has been estimated to cost $\$ 515$ for 24 weeks [190]. Given that the recent Dutch EAP program for Nivolumab in pre-treated MPM patients demonstrates a median OS of 6.7 months $[68,69]$, whilst most trials of vinorelbine in the same setting have a median OS of approximately 9-11 months [191, 192], the question arises if the cost of checkpoint inhibitors in the second line setting will limit use.

\section{Conclusions}

The following sections have described the current stateof-play as regards immunotherapy in MPM. A significant number of studies are investigating checkpoint inhibitors as both monotherapy or in combination therapy in both the front-line and salvage settings. Treatment combinations designed to recruit more immune cells to the tumor such as oncolytic viruses or those that target the interferon pathway hold promise. CAR-T therapy is emerging as a new avenue of approach for immunotherapy in MPM. 
Despite impressive durable responses, immune checkpoint inhibitors do not provide a long-term benefit to the majority of patients with cancer [193]. The data arising from immune checkpoint inhibitor studies in MPM has resulted in one FDA approval for a combination checkpoint inhibitor for the first-line treatment of unresectable MPM. The only other approval is for second-line therapy in the salvage setting and is restricted to Japan. Overall, this would suggest that these agents will shortly become part of the frontline treatment options for MPM in the coming years. Given the data from Checkpoint-743 it would seem that nivolumab/ipilimumab should be used in the first line setting, however, cost reimbursement may limit their uptake [194]. The issue of whether or not to give it to all comers irrespective of histology and PD-L1 status has however yet to be resolved given the data that suggests PD-L1 negative tumors have better responses to chemotherapy, and that patients with the sarcomatoid histology may be better candidates for checkpoint inhibitors $[53,153,195]$. Indeed it may be that PD-L1 negative non-sarcomatoid patients should initially be treated with a chemotherapy regimen and then proceed to a checkpoint inhibitor in the salvage setting upon progression, whilst PD-L1 positive patients should be offered first-line nivolumab/ipilimumab. Overall, it would appear that additional studies will be required to further delineate these issues, and improve our understanding of the immune system as a therapeutic target in MPM. Moreover, many new potential checkpoints have yet to be studied for their therapeutic potential in MPM. All these plus the existing checkpoint inhibitors will require the development of new biomarkers for patient stratification, response and also for predicting or monitoring the emergence of resistance to these agents in MPM patients.

\footnotetext{
Abbreviations

BTN3: Butyrophilin subfamily 3; CAR: Chimeric antigen receptors; CR: Clinical response; CT: Computed tomography; DC: Dendritic cell; DCR: Disease control rate; DLT: Dose limiting toxicity; ECOG: Eastern Cooperative Oncology Group; EPP: Extra-pleural pneumonectomy; EZH2: Enhancer of Zeste 2; FAP: Fibroblast activation protein; FDA: Food and Drug Administration; GEP: Gene expression profile; GM-CSF: Granulocyte macrophage colony-stimulating factor; HDACi: Histone deacetylase inhibitors; HITOC: Hyperthermic intrathoracic chemoperfusion; HLA: Human leukocyte antigen; HRR: Homologous recombination repair; IFN: Interferon; IL-2: Interleukin-2; LAG-3: Lymphocyte activation gene-3; NSCLC: Non-small cell lung cancer; NK: Natural killer; MET: MET protooncogene; MLSN: Mesothelin; MPM: Malignant pleural mesothelioma; MTD: Maximum tolerated dose; ORR: Overall response rate; OS: Overall survival; PARP: Poly ADP ribose polymerase; PD: Progressive disease; P/D: Pleurectomy with decortication; PET/CT: Positron emission tomographycomputed tomography; PFS: Progressive free survival; PR: Partial response; QoL: Quality of life; RECIST: Response evaluation criteria in solid tumors; SBRT: Stereotactic body radiotherapy; SOC: Standard of care; TCGA: The cancer genome atlas; TIM3: T-cell immunoglobulin and mucin-domain containing-3; TLR:Toll-like receptor; TMB:Tumor mutational burden; TNF-a: Tumor necrosis
}

factor alpha; TNFRSF: TNF receptor superfamily; TTF: Tumor treating fields; VATS: Video-assisted thoracoscopic surgery; VEGF: Vascular endothelial growth factor; VISTA: V-type immunoglobulin domain-containing suppressor of T cell activation.

\section{Acknowledgements}

Not applicable.

\section{Authors' contributions}

SGG conceived the review, wrote and revised the manuscript and conducted all analyses included in the manuscript. All authors read and approved the final manuscript.

\section{Funding}

The author declares no funding support for this study.

\section{Availability of data and materials}

The datasets analyzed during the current study are available in the following repositories: Oncomine: https://www.oncomine.org/resource/login.html [76] UALCAN: http://ualcan.path.uab.edu/ [78].

\section{Declarations}

Ethics approval and consent to participate

Not applicable.

Consent for publication

Not applicable.

\section{Competing interests}

The author declares that he has no competing interests.

\section{Author details}

${ }^{1}$ Thoracic Oncology Research Group, Central Pathology Laboratory, CPL 30, TCDSJ Cancer Institute, St James's Hospital, Dublin D08 RX0X, Ireland. ${ }^{2}$ Department of Clinical Medicine, Trinity College Dublin, Dublin, Ireland. ${ }^{3}$ School of Biology, Technical University of Dublin, Dublin, Ireland.

Received: 27 November 2020 Accepted: 25 April 2021

Published online: 05 May 2021

\section{References}

1. Carbone M, Adusumilli PS, Alexander HR Jr, Baas P, Bardelli F, Bononi A, Bueno R, Felley-Bosco E, Galateau-Salle F, Jablons D, et al. Mesothelioma: scientific clues for prevention, diagnosis, and therapy. CA Cancer J Clin. 2019;69(5):402-29.

2. Chen T, Sun XM, Wu L. High time for complete ban on asbestos use in developing countries. JAMA Oncol. 2019;5(6):779-80.

3. Frank AL. Global use of asbestos-legitimate and illegitimate issues. J Occup Med Toxicol. 2020;15:16.

4. van Zandwijk N, Reid G, Frank AL. Asbestos-related cancers: the "Hidden Killer" remains a global threat. Expert Rev Anticancer Ther. 2020;20(4):271-8.

5. Carbone M, Baris YI, Bertino P, Brass B, Comertpay S, Dogan AU, Gaudino G, Jube S, Kanodia S, Partridge CR, et al. Erionite exposure in North Dakota and Turkish villages with mesothelioma. Proc Natl Acad Sci U S A. 2011;108(33):13618-23.

6. Carbone M, Ly BH, Dodson RF, Pagano I, Morris PT, Dogan UA, Gazdar AF, Pass HI, Yang H. Malignant mesothelioma: facts, myths, and hypotheses. J Cell Physiol. 2012;227(1):44-58.

7. Maher B. Epidemiology: fear in the dust. Nature. 2010;468(7326):884-5.

8. Borrelli E, Babcock Z, Kogut S. Costs of medical care for mesothelioma. Rare Tumors. 2019;11:2036361319863498.

9. Buresti G, Colonna F, Corfiati M, Valenti A, Persechino B, Marinaccio A, Rondinone BM, lavicoli S. Economic impact of malignant mesothelioma in Italy: an estimate of the public and social costs. Med Lav. 2017;108(5):358-66. 
10. Tompa E, Kalcevich C, McLeod C, Lebeau M, Song C, McLeod K, Kim J, Demers PA. The economic burden of lung cancer and mesothelioma due to occupational and para-occupational asbestos exposure. Occup Environ Med. 2017;74(11):816-22.

11. Kindler HL, Ismaila N, Armato SG 3rd, Bueno R, Hesdorffer M, Jahan T, Jones CM, Miettinen M, Pass H, Rimner A, et al. Treatment of malignant pleural mesothelioma: american society of clinical oncology clinical practice guideline. J Clin Oncol. 2018;36(13):1343-73.

12. Vogelzang NJ, Rusthoven JJ, Symanowski J, Denham C, Kaukel E, Ruffie P, Gatzemeier U, Boyer M, Emri S, Manegold C, et al. Phase III study of pemetrexed in combination with cisplatin versus cisplatin alone in patients with malignant pleural mesothelioma. J Clin Oncol. 2003;21(14):2636-44.

13. Zalcman G, Mazieres J, Margery J, Greillier L, Audigier-Valette C, MoroSibilot D, Molinier O, Corre R, Monnet I, Gounant V, et al. Bevacizumab for newly diagnosed pleural mesothelioma in the Mesothelioma Avastin Cisplatin Pemetrexed Study (MAPS): a randomised, controlled, open-label, phase 3 trial. Lancet. 2016;387(10026):1405-14.

14. Brosseau S, Assoun S, Naltet C, Steinmetz C, Gounant V, Zalcman G. A review of bevacizumab in the treatment of malignant pleural mesothelioma. Future Oncol. 2017;13(28):2537-46.

15. Nowak AK, Brosseau S, Cook A, Zalcman G. Antiangiogeneic strategies in mesothelioma. Front Oncol. 2020;10:126.

16. Ehrlich P. Ueber den jetzigen stand der karzinomforschung. Ned Tijdschr Geneeskd. 1909:5:73-209.

17. Varadé J, Magadán S, González-Fernández Á. Human immunology and immunotherapy: main achievements and challenges. Cell Mol Immunol. 2020;8:1-24.

18. Locy H, de Mey S, de Mey W, De Ridder M, Thielemans K, Maenhout SK. Immunomodulation of the tumor microenvironment: turn foe into friend. Front Immunol. 2018:9:2909.

19. Nowak AK, McDonnell A, Cook A. Immune checkpoint inhibition for the treatment of mesothelioma. Expert Opin Biol Ther. 2019;19(7):697-706.

20. Murthy V, Katzman D, Sterman DH. Intrapleural immunotherapy: an update on emerging treatment strategies for pleural malignancy. Clin Respir J. 2019;13(5):272-9.

21. Lucchi M, Chella A, Melfi F, Dini P, Ambrogi M, Fino L, Fontanini G, Mussi A: A phase ll study of intrapleural immuno-chemotherapy, pleurectomy/decortication, radiotherapy, systemic chemotherapy and longterm sub-cutaneous IL-2 in stage II-III malignant pleural mesothelioma. Eur J Cardiothorac Surg. 2007;31 (3):529-533; discussion 533-524.

22. Jackaman C, Lansley S, Allan JE, Robinson BW, Nelson DJ. IL-2/CD40driven NK cells install and maintain potency in the anti-mesothelioma effector/memory phase. Int Immunol. 2012;24(6):357-68.

23. Field AK, Young CW, Krakoff IH, Tytell AA, Lampson GP, Nemes MM, Hilleman MR. Induction of interferon in human subjects by poly $\mathrm{l}: \mathrm{C}$. Proc Soc Exp Biol Med. 1971;136(4):1180-6.

24. Boutin C, Viallat JR, Astoul P. Treatment of mesothelioma with interferon gamma and interleukin 2. Rev Pneumol Clin. 1990;46(5):211-5.

25. Boutin C, Nussbaum E, Monnet I, Bignon J, Vanderschueren R, Guerin $J$ C, Menard O, Mignot P, Dabouis G, Douillard JY. Intrapleural treatment with recombinant gamma-interferon in early stage malignant pleural mesothelioma. Cancer. 1994;74(9):2460-7.

26. Parra HS, Tixi L, Latteri F, Bretti S, Alloisio M, Gravina A, Lionetto R, Bruzzi P, Dani C, Rosso R, et al. Combined regimen of cisplatin, doxorubicin, and alpha-2b interferon in the treatment of advanced malignant pleural mesothelioma: a phase II multicenter trial of the Italian Group on Rare Tumors (GITR) and the Italian Lung Cancer Task Force (FONICAP). Cancer. 2001;92(3):650-6.

27. Soulie P, Ruffie P, Trandafir L, Monnet I, Tardivon A, Terrier P, Cvitkovic E, Le Chevalier T, Armand JP. Combined systemic chemoimmunotherapy in advanced diffuse malignant mesothelioma. Report of a phase I-II study of weekly cisplatin/interferon alfa-2a. J Clin Oncol. 1996;14(3):878-85.

28. Upham JW, Musk AW, van Hazel G, Byrne M, Robinson BW. Interferon alpha and doxorubicin in malignant mesothelioma: a phase II study. Aust N Z J Med. 1993;23(6):683-7.

29. Monnet I, Breau JL, Moro D, Lena H, Eymard JC, Menard O, Vuillez JP, Chokri M, Romet-Lemonne JL, Lopez M. Intrapleural infusion of activated macrophages and gamma-interferon in malignant pleural mesothelioma: a phase II study. Chest. 2002;121(6):1921-7.
30. Pass HI, Temeck BK, Kranda K, Thomas G, Russo A, Smith P, FriaufW, Steinberg SM. Phase III randomized trial of surgery with or without intraoperative photodynamic therapy and postoperative immunochemotherapy for malignant pleural mesothelioma. Ann Surg Oncol. 1997:4(8):628-33.

31. Macedo N, Miller DM, Haq R, Kaufman HL. Clinical landscape of oncolytic virus research in 2020. J Immunother Cancer. 2020;8(2):8.

32. Yan WL, Shen KY, Tien CY, Chen YA, Liu SJ. Recent progress in GM-CSFbased cancer immunotherapy. Immunotherapy. 2017;9(4):347-60.

33. Dirix LY, van Meerbeeck J, Schrijvers D, Corthouts B, Prove A, van Marck E, Vermeire P, van Oosterom AT. A phase II trial of dose-escalated doxorubicin and ifosfamide/mesna in patients with malignant mesothelioma. Ann Oncol. 1994;5(7):653-5.

34. Davidson JA, Musk AW, Wood BR, Morey S, Ilton M, Yu LL, Drury P, Shilkin K, Robinson BW. Intralesional cytokine therapy in cancer: a pilot study of GM-CSF infusion in mesothelioma. J Immunother. 1998;21 (5):389-98,

35. Kosty MP, Herndon JE 2nd, Vogelzang NJ, Kindler HL, Green MR. Highdose doxorubicin, dexrazoxane, and GM-CSF in malignant mesothelioma: a phase II study-Cancer and Leukemia Group B 9631. Lung Cancer. 2001;34(2):289-95.

36. Powell A, Creaney J, Broomfield S, Van Bruggen I, Robinson B. Recombinant GM-CSF plus autologous tumor cells as a vaccine for patients with mesothelioma. Lung Cancer. 2006;52(2):189-97.

37. Khanna S, Graef S, Mussai F, Thomas A, Wali N, Yenidunya BG, Yuan C, Morrow B, Zhang J, Korangy F, et al. Tumor-derived GM-CSF promotes granulocyte immunosuppression in mesothelioma patients. Clin Cancer Res. 2018;24(12):2859-72.

38. Tsao AS, Lindwasser OW, Adjei AA, Adusumilli PS, Beyers ML, Blumenthal GM, Bueno R, Burt BM, Carbone M, Dahlberg SE, et al. Current and future management of malignant mesothelioma: a consensus report from the National Cancer Institute Thoracic Malignancy Steering Committee, International Association for the Study of Lung Cancer, and Mesothelioma Applied Research Foundation. J Thorac Oncol. 2018;13(11):1655-67.

39. Opitz I, Furrer K. Preoperative Identification of benefit from surgery for malignant pleural mesothelioma. Thorac Surg Clin. 2020;30(4):435-49.

40. Friedberg JS, Culligan MJ, Tsao AS, Rusch V, Sepesi B, Pass HI, Bueno R, Burt B, Sugarbaker DJ, de Perrot M, et al. A proposed system toward standardizing surgical-based treatments for malignant pleural mesothelioma, From the Joint National Cancer Institute-International Association for the Study of Lung Cancer-Mesothelioma Applied Research Foundation Taskforce. J Thorac Oncol. 2019;14(8):1343-53.

41. Gomez DR, Rimner A, Simone CB II, Cho BCJ, de Perrot M, Adjei AA, Bueno R, Gill RR, Harpole DH Jr, Hesdorffer M, et al. The use of radiation therapy for the treatment of malignant pleural mesothelioma: expert opinion from the National Cancer Institute Thoracic Malignancy Steering Committee, International Association for the Study of Lung Cancer, and Mesothelioma Applied Research Foundation. JThorac Oncol. 2019;14(7):1172-83.

42. Opitz I, Scherpereel A, Berghmans T, Psallidas I, Glatzer M, Rigau D, Astoul P, Bölükbas S, Boyd J, Coolen J, et al. ERS/ESTS/EACTS/ESTRO guidelines for the management of malignant pleural mesothelioma. Eur J Cardiothorac Surg. 2020:58(1):1-24.

43. O'Donnell JS, Hoefsmit EP, Smyth MJ, Blank CU, Teng MWL. The promise of neoadjuvant immunotherapy and surgery for cancer treatment. Clin Cancer Res. 2019.

44. Wei SC, Duffy CR, Allison JP. Fundamental mechanisms of immune checkpoint blockade therapy. Cancer Discov. 2018;8(9):1069-86.

45. van den Ende T, van den Boorn HG, Hoonhout NM, van Etten-Jamaludin FS, Meijer SL, Derks S, de Gruijl TD, Bijlsma MF, van Oijen MGH, van Laarhoven HWM. Priming the tumor immune microenvironment with chemo(radio)therapy: a systematic review across tumor types. Biochim Biophys Acta Rev Cancer. 2020;1874(1):188386.

46. Kindler H, Ferguson M, Tan Y-H, Rose B, Ahmad M, Armato S, Straus C, Karrison T, Seiwert T. P2.06-029 pilot window-of-opportunity study of pembrolizumab in patients with resectable malignant pleural mesothelioma (MPM): topic: mesothelioma and SCLC. J Thoracic Oncol. 2017;12(1):S1089.

47. Gray SG, Mutti L. Immunotherapy for mesothelioma: a critical review of current clinical trials and future perspectives. Transl Lung Cancer Res. 2020;9(Suppl 1):S100-19. 
48. Reuss JE, Forde PM. Immunotherapy for mesothelioma: rationale and new approaches. Clin Adv Hematol Oncol. 2020;18(9):562-72.

49. Reuss JE, Sepesi B, Rolfo CD, Zahurak M, Anagnostou V, Smith KN, Cottrell T, Stein JE, Illei PB, Taube JM, et al. Trial in progress: neoadjuvant immune checkpoint blockade in resectable malignant pleural mesothelioma. J Clin Oncol. 2020;38(15):9078-9078.

50. Shah R, Klotz LV, Chung I, Feißt M, Schneider MA, Riedel J, Bischoff H, Eichhorn ME, Thomas M. A phase II trial of nivolumab with chemotherapy followed by maintenance nivolumab in patients with pleural mesothelioma after surgery: The NICITA Study Protocol. Clin Lung Cancer. 2020.

51. Nowak AK, Lesterhuis WJ, Kok PS, Brown C, Hughes BG, Karikios DJ, John T, Kao SC, Leslie C, Cook AM, et al. Durvalumab with first-line chemotherapy in previously untreated malignant pleural mesothelioma (DREAM): a multicentre, single-arm, phase 2 trial with a safety run-in. Lancet Oncol. 2020;21(9):1213-23.

52. Forde PM, Sun Z, Anagnostou V, Kindler HL, Purcell WT, Goulart BHL, Dudek AZ, Borghaei H, Brahmer JR, Ramalingam SS. PrE0505: phase II multicenter study of anti-PD-L1, durvalumab, in combination with cisplatin and pemetrexed for the first-line treatment of unresectable malignant pleural mesothelioma (MPM)—a PrECOG LLC study. J Clin Oncol. 2020;38(15):9003-9003.

53. Baas P, Scherpereel A, Nowak AK, Fujimoto N, Peters S, Tsao AS, Mansfield AS, Popat S, Jahan T, Antonia S, et al. First-line nivolumab plus ipilimumab in unresectable malignant pleural mesothelioma (CheckMate 743): a multicentre, randomised, open-label, phase 3 trial. Lancet. 2021.

54. Wright K. FDA approves nivolumab plus ipilimumab for previously untreated unresectable malignant pleural mesothelioma. Oncology (Williston Park). 2020;34(11):502-3.

55. Okada M, Kijima T, Aoe K, Kato T, Fujimoto N, Nakagawa K, Takeda Y, Hida T, Kanai K, Imamura F, et al. Clinical efficacy and safety of nivolumab: results of a multicenter, open-label, single-arm, Japanese phase II study in malignant pleural mesothelioma (MERIT). Clin Cancer Res. 2019;25(18):5485-92.

56. Mansfield AS, Zauderer MG. Nivo-lution in mesothelioma. Clin Cancer Res. 2019;25(18):5438-40.

57. Maio M, Scherpereel A, Calabro L, Aerts J, Cedres Perez S, Bearz A, Nackaerts K, Fennell DA, Kowalski D, Tsao AS, et al. Tremelimumab as secondline or third-line treatment in relapsed malignant mesothelioma (DETERMINE): a multicentre, international, randomised, double-blind, placebo-controlled phase 2b trial. Lancet Oncol. 2017;18(9):1261-73.

58. Popat S, Curioni-Fontecedro A, Dafni U, Shah R, O'Brien M, Pope A Fisher P, Spicer J, Roy A, Gilligan D, et al. A multicentre randomised phase III trial comparing pembrolizumab versus single-agent chemotherapy for advanced pre-treated malignant pleural mesothelioma: the European Thoracic Oncology Platform (ETOP 9-15) PROMISE-meso trial. Ann Oncol. 2020;31(12):1734-45.

59. Quispel-Janssen J, van der Noort V, de Vries JF, Zimmerman M, Lalezari F, Thunnissen E, Monkhorst K, Schouten R, Schunselaar L, Disselhorst $M$, et al. Programmed death 1 blockade with nivolumab in patients with recurrent malignant pleural mesothelioma. J Thorac Oncol. 2018;13(10):1569-76.

60. Hassan R, Thomas A, Nemunaitis JJ, Patel MR, Bennouna J, Chen FL, Delord JP, Dowlati A, Kochuparambil ST, Taylor MH, et al. Efficacy and safety of avelumab treatment in patients with advanced unresectable mesothelioma: phase $1 \mathrm{~b}$ results from the JAVELIN solid tumor trial. JAMA Oncol. 2019:5(3):351-7.

61. Ott PA, Bang YJ, Piha-Paul SA, Razak ARA, Bennouna J, Soria JC, Rugo HS, Cohen RB, O'Neil BH, Mehnert JM, et al. T-cell-inflamed gene-expression profile, programmed death ligand 1 expression, and tumor mutational burden predict efficacy in patients treated with pembrolizumab across 20 cancers: KEYNOTE-028. J Clin Oncol. 2019;37(4):318-27.

62. Alley EW, Lopez J, Santoro A, Morosky A, Saraf S, Piperdi B, van Brummelen $\mathrm{E}$. Clinical safety and activity of pembrolizumab in patients with malignant pleural mesothelioma (KEYNOTE-028): preliminary results from a non-randomised, open-label, phase $1 \mathrm{~b}$ trial. Lancet Oncol. 2017;18(5):623-30.

63. Marabelle A, Fakih M, Lopez J, Shah M, Shapira-Frommer R, Nakagawa K, Chung HC, Kindler HL, Lopez-Martin JA, Miller WH Jr, et al. Association of tumour mutational burden with outcomes in patients with advanced solid tumours treated with pembrolizumab: prospective biomarker analysis of the multicohort, open-label, phase $2 \mathrm{KEY}$ NOTE-158 study. Lancet Oncol. 2020;21(10):1353-65.

64. Desai A, Karrison T, Rose B, Tan Y, Hill B, Pemberton E, Straus C, Seiwert T, Kindler HL. OA08.03 phase II trial of pembrolizumab (NCT02399371) in previously-treated malignant mesothelioma (MM): final analysis. J Thorac Oncol. 2018;13(10):S339.

65. Hotta K, Fujimoto N, Kozuki T, Aoe K, Kiura K. Nivolumab for the treatment of unresectable pleural mesothelioma. Expert Opin Biol Ther. 2020:20(2):109-14.

66. Forde PM, Scherpereel A, Tsao AS. Use of immune checkpoint inhibitors in mesothelioma. Curr Treat Options Oncol. 2019;20(2):18.

67. Fennell DA. Nivolumab versus placebo in relapsed malignant mesothelioma: The CONFIRM phase 3 trial. J Thoracic Oncol. 2021;16:11.

68. Belderbos RA. Nivolumab in recurrent malignant pleural mesothelioma: real-world data from expanded access program in The Netherlands. J Thoracic Oncol. 2021;16:06.

69. Cantini L, Belderbos RA, Gooijer CJ, Dumoulin DW, Cornelissen R, Baart S, Burgers JA, Baas P, Aerts J. Nivolumab in pre-treated malignant pleural mesothelioma: real-world data from the Dutch expanded access program. TransI Lung Cancer Res. 2020;9(4):1169-79.

70. Scherpereel A, Mazieres J, Greillier L, Lantuejoul S, Do P, Bylicki O, Monnet I, Corre R, Audigier-Valette C, Locatelli-Sanchez M, et al. Nivolumab or nivolumab plus ipilimumab in patients with relapsed malignant pleural mesothelioma (IFCT-1501 MAPS2): a multicentre, open-label, randomised, non-comparative, phase 2 trial. Lancet Oncol. 2019;20(2):239-53.

71. Calabrò L, Morra A, Giannarelli D, Amato G, D'Incecco A, Covre A, Lewis A, Rebelatto MC, Danielli R, Altomonte M, et al. Tremelimumab combined with durvalumab in patients with mesothelioma (NIBIT-MESO-1): an open-label, non-randomised, phase 2 study. Lancet Respir Med. 2018;6(6):451-60

72. Disselhorst MJ, Quispel-Janssen J, Lalezari F, Monkhorst K, de Vries JF, van der Noort V, Harms E, Burgers S, Baas P. Ipilimumab and nivolumab in the treatment of recurrent malignant pleural mesothelioma (INITIATE): results of a prospective, single-arm, phase 2 trial. Lancet Respir Med. 2019;7(3):260-70.

73. Bibby A, Maskell N. Checkpoint inhibitors in mesothelioma: hope for the future? Lancet Oncol. 2019;20(2):172-4.

74. Mankor JM, Disselhorst MJ, Poncin M, Baas P, Aerts J, Vroman H. Efficacy of nivolumab and ipilimumab in patients with malignant pleural mesothelioma is related to a subtype of effector memory cytotoxic T cells: translastional evidence from two clinical trials. EBioMedicine. 2020;62:103040

75. Venkatraman D, Anderson A, Digumarthy S, Lizotte PH, Awad MM. Phase 2 study of tremelimumab plus durvalumab for previouslytreated malignant pleural mesothelioma (MPM). J Clin Oncol. 2019:37(15):8549-8549.

76. Rhodes DR, Kalyana-Sundaram S, Mahavisno V, Varambally R, Yu J, Briggs BB, Barrette TR, Anstet MJ, Kincead-Beal C, Kulkarni P, et al. Oncomine 3.0: genes, pathways, and networks in a collection of 18,000 cancer gene expression profiles. Neoplasia. 2007;9(2):166-80.

77. Gordon GJ, Rockwell GN, Jensen RV, Rheinwald JG, Glickman JN, Aronson JP, Pottorf BJ, Nitz MD, Richards WG, Sugarbaker DJ, et al. Identification of novel candidate oncogenes and tumor suppressors in malignant pleural mesothelioma using large-scale transcriptional profiling. Am J Pathol. 2005;166(6):1827-40.

78. Chandrashekar DS, Bashel B, Balasubramanya SAH, Creighton CJ, Ponce-Rodriguez I, Chakravarthi B, Varambally S. UALCAN: a portal for facilitating tumor subgroup gene expression and survival analyses. Neoplasia. 2017;19(8):649-58.

79. Maruhashi T, Sugiura D, Okazaki IM, Okazaki T. LAG-3: from molecular functions to clinical applications. J Immunother Cancer. 2020;8(2):6.

80. Marcq E, Pauwels P, van Meerbeeck JP, Smits EL. Targeting immune checkpoints: new opportunity for mesothelioma treatment? Cancer Treat Rev. 2015;41(10):914-24.

81. Marcq E, Waele J, Audenaerde JV, Lion E, Santermans E, Hens N, Pauwels $P$, van Meerbeeck JP, Smits ELJ. Abundant expression of TIM-3, LAG-3, PD-1 and PD-L1 as immunotherapy checkpoint targets in effusions of mesothelioma patients. Oncotarget. 2017;8(52):89722-35.

82. Salaroglio IC, Kopecka J, Napoli F, Pradotto M, Maletta F, Costardi L, Gagliasso M, Milosevic V, Ananthanarayanan P, Bironzo P, et al. Potential 
diagnostic and prognostic role of microenvironment in malignant pleural mesothelioma. J Thorac Oncol. 2019;14(8):1458-71.

83. Wu C, Mairinger F, Casanova R, Batavia AA, Leblond AL, Soltermann A. Prognostic immune cell profiling of malignant pleural effusion patients by computerized immunohistochemical and transcriptional analysis. Cancers (Basel). 2019;11:12.

84. Chen F. Immunohistochemistry analyses of LAG-3 expression across different tumor types and co-expression with PD-1. In: 2020; ASCO Virtual Scientific Program. American Society of Clinical Oncology.

85. Marcq E, Van Audenaerde JRM, De Waele J, Merlin C, Pauwels P, van Meerbeeck JP, Fisher SA, Smits ELJ. The search for an interesting partner to combine with PD-L1 Blockade in mesothelioma: focus on TIM-3 and LAG-3. Cancers (Basel). 2021;13:2.

86. Luke JJ. A phase I, first-in-human, open-label, dose-escalation study of MGD013, a bispecific DART molecule binding PD-1 and LAG-3, in patients with unresectable or metastatic neoplasms. In: 2020; ASCO Virtual Scientific Program. American Society of Clinical Oncology.

87. Hmeljak J, Sanchez-Vega F, Hoadley KA, Shih J, Stewart C, Heiman D, Tarpey P, Danilova L, Drill E, Gibb EA, et al. Integrative molecular characterization of malignant pleural mesothelioma. Cancer Discov. 2018;8(12):1548-65.

88. Chung YS, Kim M, Cha YJ, Kim KA, Shim HS. Expression of V-set immunoregulatory receptor in malignant mesothelioma. Mod Pathol. 2020;33(2):263-70.

89. Muller S, Victoria Lai W, Adusumilli PS, Desmeules P, Frosina D, Jungbluth A, Ni A, Eguchi T, Travis WD, Ladanyi M, et al. V-domain Ig-containing suppressor of T-cell activation (VISTA), a potentially targetable immune checkpoint molecule, is highly expressed in epithelioid malignant pleural mesothelioma. Mod Pathol. 2020;33(2):303-11.

90. Alcala N, Mangiante L, Le-Stang N, Gustafson CE, Boyault S, Damiola F, Alcala K, Brevet M, Thivolet-Bejui F, Blanc-Fournier C, et al. Redefining malignant pleural mesothelioma types as a continuum uncovers immune-vascular interactions. EBioMedicine. 2019;48:191-202.

91. Zauderer M, Brody J, Thomas Marron T, Pacey S, Martell R, Wang H, Spicer J. O28 First-in-class small molecule CA-170 targeting VISTA: a report on efficacy outcomes from a cohort of 12 malignant pleural mesothelioma (MPM) patients in study CA-170-101. J Immunother Cancer. 2019;7(Suppl 1):201.

92. Calabrò L, Sigalotti L, Fonsatti E, Bertocci E, Di Giacomo AM, Danielli R, Cutaia O, Colizzi F, Covre A, Mutti L, et al. Expression and regulation of B7-H3 immunoregulatory receptor, in human mesothelial and mesothelioma cells: immunotherapeutic implications. J Cell Physiol. 2011;226(10):2595-600.

93. Aggarwal C, Joshua A, Ferris R, Antonia S, Rahma O, Tolcher A, Cohen RB, Lou Y, Hauke R, Vogelzang NJ, et al. 33rd Annual Meeting \& PreConference Programs of the Society for Immunotherapy of Cancer (SITC 2018) - O24 - A Phase 1, Open-Label, Dose Escalation Study of Enoblituzumab in Combination with Pembrolizumab in Patients with Select Solid Tumors. J Immunother Cancer. 2018;6(1):115.

94. Matsumura E, Kajino K, Abe M, Ohtsuji N, Saeki H, Hlaing MT, Hino O. Expression status of PD-L1 and B7-H3 in mesothelioma. Pathol Int. 2020

95. Powderly JD. Preliminary dose escalation results from a phase $\mathrm{I} / \mathrm{Il}$, firstin-human study of MGC018 (anti-B7-H3 antibody-drug conjugate) in patients with advanced solid tumors. In: 2020; ASCO Virtual Scientific Program. American Society of Clinical Oncology.

96. Anderson AC. Tim-3: an emerging target in the cancer immunotherapy landscape. Cancer Immunol Res. 2014;2(5):393-8.

97. Saleh R, Toor SM, Elkord E. Targeting TIM-3 in solid tumors: innovations in the preclinical and translational realm and therapeutic potential. Expert Opin Ther Targets. 2020;1-12.

98. Acharya N, Sabatos-Peyton C, Anderson AC. Tim-3 finds its place in the cancer immunotherapy landscape. J Immunother Cancer. 2020;8:1.

99. Awad MM, Jones RE, Liu H, Lizotte PH, Ivanova EV, Kulkarni M, HerterSprie GS, Liao X, Santos AA, Bittinger MA, et al. Cytotoxic T cells in PD-L1-positive malignant pleural mesotheliomas are counterbalanced by distinct immunosuppressive factors. Cancer Immunol Res 2016:4(12):1038-48.

100. Marcq E, Siozopoulou V, De Waele J, van Audenaerde J, Zwaenepoel K, Santermans E, Hens N, Pauwels P, van Meerbeeck JP, Smits EL. Prognostic and predictive aspects of the tumor immune microenvironment and immune checkpoints in malignant pleural mesothelioma. Oncoimmunology. 2017;6(1):e1261241.

101. Chauvin JM, Zarour HM. TIGIT in cancer immunotherapy. J Immunother Cancer. 2020;8:2.

102. Klampatsa A, O'Brien SM, Thompson JC, Rao AS, Stadanlick JE, Martinez MC, Liousia M, Cantu E, Cengel K, Moon EK, et al. Phenotypic and functional analysis of malignant mesothelioma tumor-infiltrating lymphocytes. Oncoimmunology. 2019;8(9):e1638211.

103. Dolgin E. Antibody engineers seek optimal drug targeting TIGIT checkpoint. Nat Biotechnol. 2020;38(9):1007-9.

104. Rhodes DA, Reith W, Trowsdale J. Regulation of immunity by butyrophilins. Annu Rev Immunol. 2016;34:151-72.

105. Gentles AJ, Newman AM, Liu CL, Bratman SV, Feng W, Kim D, Nair VS, Xu Y, Khuong A, Hoang CD, et al. The prognostic landscape of genes and infiltrating immune cells across human cancers. Nat Med. 2015;21(8):938-45.

106. Marabelle A, Jungels C, Bono JD, Vey N, Wermke M, Garralda E, Gassart $A D$, Brune $P$, Valentin E, Iché $M$, et al. 316 EVICTION Study: Preliminary results in solid tumor patients with ICT01, a first-in-class, gamma9 delta2 $\mathrm{T}$ cell activating antibody targeting butyrophilin-3A. J Immunother Cancer. 2020;8(3):342.

107. Fear VS, Tilsed C, Chee J, Forbes CA, Casey T, Solin JN, Lansley SM, Joost Lesterhuis W, Dick IM, Nowak AK, et al. Combination immune checkpoint blockade as an effective therapy for mesothelioma. Oncoimmunology. 2018;7(10):e1494111.

108. Fromm G, de Silva S, Johannes K, Patel A, Hornblower JC, Schreiber TH. Agonist redirected checkpoint, PD1-Fc-OX40L, for cancer immunotherapy. J Immunother Cancer. 2018;6(1):149.

109. Sterman DH, Alley E, Stevenson JP, Friedberg J, Metzger S, Recio A, Moon EK, Haas AR, Vachani A, Katz SI, et al. Pilot and feasibility trial evaluating immuno-gene therapy of malignant mesothelioma using intrapleural delivery of adenovirus-IFNalpha combined with chemotherapy. Clin Cancer Res. 2016;22(15):3791-800.

110. Sterman DH, Haas A, Moon E, Recio A, Schwed D, Vachani A, Katz SI, Gillespie $C T$, Cheng G, Sun J, et al. A trial of intrapleural adenoviralmediated Interferon-alpha2b gene transfer for malignant pleural mesothelioma. Am J Respir Crit Care Med. 2011;184(12):1395-9.

111. Sterman DH, Recio A, Haas AR, Vachani A, Katz SI, Gillespie CT, Cheng G, Sun J, Moon E, Pereira L, et al. A phase I trial of repeated intrapleural adenoviral-mediated interferon-beta gene transfer for mesothelioma and metastatic pleural effusions. Mol Ther. 2010;18(4):852-60.

112. Achard C, Boisgerault N, Delaunay T, Roulois D, Nedellec S, Royer PJ, Pain M, Combredet C, Mesel-Lemoine M, Cellerin L, et al. Sensitivity of human pleural mesothelioma to oncolytic measles virus depends on defects of the type I interferon response. Oncotarget. 2015;6(42):44892-904.

113. Delaunay T, Achard C, Boisgerault N, Grard M, Petithomme T, Chatelain C, Dutoit S, Blanquart C, Royer PJ, Minvielle S, et al. Frequent homozygous deletions of type I interferon genes in pleural mesothelioma confer sensitivity to oncolytic measles virus. J Thorac Oncol. 2020;15(5):827-42.

114. Pistillo MP, Carosio R, Banelli B, Morabito A, Mastracci L, Ferro P, Varesano S, Venè R, Poggi A, Roncella S. IFN- $\gamma$ upregulates membranous and soluble PD-L1 in mesothelioma cells: potential implications for the clinical response to PD-1/PD-L1 blockade. Cell Mol Immunol. 2020;17(4):410-1.

115. Jaderberg M, Cedres S, Paz-Ares L, Serres X, Ricordel C, Isambert N, Aix SP, Levitsky V, Kuryk L, Moller A-S, et al. 361 A randomised open-label phase I/II study adding ONCOS-102 to pemetrexed/cisplatin in patients with unresectable malignant pleural mesothelioma - 12 month analysis of biomarkers and clinical outcomes. J Immunother Cancer. 2020;8(Suppl 3):A386.

116. Targovax: Targovax granted European Patent for ONCOS-102 in combination with checkpoint inhibitors. https://www.targovaxcom/en/targo vax-granted-european-patent-for-oncos-102-in-combination-withcheckpoint-inhibitors/. 2020.

117. Targovax: Targovax announces collaboration to evaluate ONCOS-102 in combination with KEYTRUDA ${ }^{\circledR}$ in mesothelioma. https://www.targo vaxcom/en/targovax-announces-collaboration-to-evaluate-oncos-102in-combination-with-keytruda-in-mesothelioma/. 2020.

118. Hosseinkhani N, Derakhshani A, Kooshkaki O, Abdoli Shadbad M, Hajiasgharzadeh K, Baghbanzadeh A, Safarpour H, Mokhtarzadeh A, Brunetti 
O, Yue SC, et al. Immune checkpoints and CAR-T cells: the pioneers in future cancer therapies? Int J Mol Sci. 2020;21:21.

119. Watanabe N, McKenna MK, Rosewell Shaw A, Suzuki M. Clinical CAR-T cell and oncolytic virotherapy for cancer treatment. Mol Ther. 2020.

120. Moon EK, Carpenito C, Sun J, Wang LC, Kapoor V, Predina J, Powell DJ Jr, Riley JL, June $\mathrm{CH}$, Albelda SM. Expression of a functional CCR2 receptor enhances tumor localization and tumor eradication by retargeted human T cells expressing a mesothelin-specific chimeric antibody receptor. Clin Cancer Res. 2011;17(14):4719-30.

121. Adusumilli PS, Cherkassky L, Villena-Vargas J, Colovos C, Servais E, Plotkin J, Jones DR, Sadelain M. Regional delivery of mesothelin-targeted CART cell therapy generates potent and long-lasting CD4-dependent tumor immunity. Sci Transl Med. 2014;6(261):261-151.

122. Schuberth $P C$, Hagedorn $C$, Jensen $S M$, Gulati $P$, van den Broek M, Mischo A, Soltermann A, Jungel A, Marroquin Belaunzaran O, Stahel R, et al. Treatment of malignant pleural mesothelioma by fibroblast activation protein-specific re-directed T cells. J Transl Med. 2013;11:187.

123. Thayaparan T, Petrovic RM, Achkova DY, Zabinski T, Davies DM, Klampatsa A, Parente-Pereira AC, Whilding LM, van der Stegen SJ, Woodman $\mathrm{N}$, et al. CART-cell immunotherapy of MET-expressing malignant mesothelioma. Oncoimmunology. 2017;6(12):e1363137.

124. Klampatsa A, Achkova DY, Davies DM, Parente-Pereira AC, Woodman N, Rosekilly J, Osborne G, Thayaparan T, Bille A, Sheaf M, et al. Intracavitary "T4 immunotherapy" of malignant mesothelioma using pan-ErbB retargeted CAR T-cells. Cancer Lett. 2017;393:52-9.

125. Klampatsa A, Haas AR, Moon EK, Albelda SM. Chimeric antigen receptor (CAR) T cell therapy for malignant pleural mesothelioma (MPM). Cancers (Basel). 2017;9:9.

126. Kiesgen S, Chicaybam L, Chintala NK, Adusumilli PS. Chimeric antigen receptor (CAR) T-cell therapy for thoracic malignancies. J Thorac Oncol. 2018:13(1):16-26.

127. Alard E, Butnariu AB, Grillo M, Kirkham C, Zinovkin DA, Newnham L, Macciochi J, Pranjol MZI. Advances in anti-cancer immunotherapy: car-T cell, checkpoint inhibitors, dendritic cell vaccines, and oncolytic viruses, and emerging cellular and molecular targets. Cancers (Basel). 2020;12:7.

128. Poorebrahim M, Melief J, Pico de Coaña Y, Cid-Arregui A, Kiessling R. Counteracting CART cell dysfunction. Oncogene. 2020;8:9.

129. John LB, Devaud C, Duong CP, Yong CS, Beavis PA, Haynes NM, Chow MT, Smyth MJ, Kershaw MH, Darcy PK. Anti-PD-1 antibody therapy potently enhances the eradication of established tumors by genemodified T cells. Clin Cancer Res. 2013;19(20):5636-46.

130. Rafiq S, Yeku OO, Jackson HJ, Purdon TJ, van Leeuwen DG, Drakes DJ, Song M, Miele MM, Li Z, Wang P, et al. Targeted delivery of a PD1-blocking scFv by CAR-T cells enhances anti-tumor efficacy in vivo. Nat Biotechnol. 2018;36(9):847-56.

131. Cherkassky L, Morello A, Villena-Vargas J, Feng Y, Dimitrov DS, Jones DR, Sadelain M, Adusumilli PS. Human CART cells with cell-intrinsic PD-1 checkpoint blockade resist tumor-mediated inhibition. J Clin Invest. 2016;126(8):3130-44

132. Cornelissen R, Hegmans JP, Maat AP, Kaijen-Lambers ME, Bezemer K, Hendriks RW, Hoogsteden HC, Aerts JG. Extended tumor control after dendritic cell vaccination with low-dose cyclophosphamide as adjuvant treatment in patients with malignant pleural mesothelioma. Am J Respir Crit Care Med. 2016;193(9):1023-31.

133. Gregoire M. Dendritic cell vaccination as a treatment modality for mesothelioma. Expert Rev Respir Med. 2010;4(3):311-4.

134. Hegmans JP, Hemmes A, Aerts JG, Hoogsteden HC, Lambrecht BN. Immunotherapy of murine malignant mesothelioma using tumor lysate-pulsed dendritic cells. Am J Respir Crit Care Med. 2005;171(10):1168-77.

135. Hegmans JP, Veltman JD, Lambers ME, de Vries IJ, Figdor CG, Hendriks RW, Hoogsteden HC, Lambrecht BN, Aerts JG. Consolidative dendritic cell-based immunotherapy elicits cytotoxicity against malignant mesothelioma. Am J Respir Crit Care Med. 2010;181(12):1383-90.

136. Peikert T, Sterman DH. Harnessing the power of the host: improving dendritic cell vaccines for malignant pleural mesothelioma. Am J Respir Crit Care Med. 2016;193(9):943-5.

137. Aerts J, de Goeje PL, Cornelissen R, Kaijen-Lambers MEH, Bezemer $\mathrm{K}$, van der Leest CH, Mahaweni NM, Kunert A, Eskens F, Waasdorp C, et al. Autologous dendritic cells pulsed with allogeneic tumor cell lysate in mesothelioma: from mouse to human. Clin Cancer Res. 2018;24(4):766-76.

138. Vroman $H$, Balzaretti G, Belderbos RA, Klarenbeek PL, van Nimwegen $M$, Bezemer K, Cornelissen R, Niewold ITG, van Schaik BD, van Kampen AH, et al. T cell receptor repertoire characteristics both before and following immunotherapy correlate with clinical response in mesothelioma. $J$ Immunother Cancer. 2020;8:1.

139. Belderbos RA, Baas P, Berardi R, Cornelissen R, Fennell DA, van Meerbeeck JP, Scherpereel A, Vroman H, Aerts J. A multicenter, randomized, phase II/III study of dendritic cells loaded with allogeneic tumor cell lysate (MesoPher) in subjects with mesothelioma as maintenance therapy after chemotherapy: DENdritic cell Immunotherapy for Mesothelioma (DENIM) trial. Transl Lung Cancer Res. 2019:8(3):280-5.

140. Mun EJ, Babiker HM, Weinberg U, Kirson ED, Von Hoff DD. Tumortreating fields: a fourth modality in cancer treatment. Clin Cancer Res. 2018;24(2):266-75.

141. Fennell DA. Tumour treating fields for mesothelioma: controversy versus opportunity. Lancet Oncol. 2019;20(12):1623-5.

142. de Gooijer CJ, Burgers JA. Tumour treating fields for mesothelioma. Lancet Oncol. 2020;21(1):e9.

143. Barbarino M, Bottaro M, Luzzi L, Giordano A, Mutti L. Tumour treating fields for mesothelioma. Lancet Oncol. 2020;21(1):e8.

144. Ceresoli GL, Gianoncelli L, Grosso F. Tumour treating fields for mesothelioma_authors' reply. Lancet Oncol. 2020;21(1):e10.

145. BusinessWire: Novocure Announces Clinical Trial Collaboration with MSD to Evaluate Tumor Treating Fields Together with KEYTRUDA ${ }^{\circledR}$ (pembrolizumab) in Non-Small Cell Lung Cancer. https://www.busin esswirecom/news/home/20200715005430/en/. 2020.

146. McNamara MG, Jacobs T, Lamarca A, Hubner RA, Valle JW, Amir E. Impact of high tumor mutational burden in solid tumors and challenges for biomarker application. Cancer Treat Rev. 2020;89:102084.

147. Sholl LM, Hirsch FR, Hwang D, Botling J, Lopez-Rios F, Bubendorf L, Mino-Kenudson M, Roden AC, Beasley MB, Borczuk A, et al. The promises and challenges of tumor mutation burden as an immunotherapy biomarker: a perspective from the International Association for the Study of Lung Cancer Pathology Committee. J Thorac Oncol. 2020;15(9):1409-24.

148. Bueno R, Stawiski EW, Goldstein LD, Durinck S, De Rienzo A, Modrusan Z, Gnad F, Nguyen TT, Jaiswal BS, Chirieac LR, et al. Comprehensive genomic analysis of malignant pleural mesothelioma identifies recurrent mutations, gene fusions and splicing alterations. Nat Genet. 2016:48(4):407-16.

149. Shao C, Li G, Huang L, Pruitt S, Castellanos E, Frampton G, Carson KR, Snow T, Singal G, Fabrizio D, et al. Prevalence of high tumor mutational burden and association with survival in patients with less common solid tumors. JAMA Netw Open. 2020;3(10):e2025109.

150. Bersanelli M. Tumour mutational burden as a driver for treatment choice in resistant tumours (and beyond). Lancet Oncol. 2020;21(10):1255-7.

151. Minchom A, Yuan W, Crespo M, Gurel B, Figueiredo I, Wotherspoon A, Miranda S, Riisnaes R, Ferreira A, Bertan C, et al. Molecular and immunological features of a prolonged exceptional responder with malignant pleural mesothelioma treated initially and rechallenged with pembrolizumab. J Immunother Cancer. 2020;8:1.

152. Uprety D. CheckMate 743: a glimmer of hope for malignant pleural mesothelioma. Clin Lung Cancer. 2020.

153. Fusco N, Vaira V, Righi I, Sajjadi E, Venetis K, Lopez G, Cattaneo M, Castellani M, Rosso L, Nosotti M, et al. Characterization of the immune microenvironment in malignant pleural mesothelioma reveals prognostic subgroups of patients. Lung Cancer. 2020;150:53-61.

154. Blum Y, Jaurand MC, De Reyniès A, Jean D. Unraveling the cellular heterogeneity of malignant pleural mesothelioma through a deconvolution approach. Mol Cell Oncol. 2019;6(4):1610322.

155. Blum Y, Meiller C, Quetel L, Elarouci N, Ayadi M, Tashtanbaeva D, Armenoult L, Montagne F, Tranchant R, Renier A, et al. Dissecting heterogeneity in malignant pleural mesothelioma through histo-molecular gradients for clinical applications. Nat Commun. 2019;10(1):1333.

156. Quetel L, Meiller C, Assié JB, Blum Y, Imbeaud S, Montagne F, Tranchant R, de Wolf J, Caruso S, Copin MC, et al. Genetic alterations of malignant pleural mesothelioma: association with tumor heterogeneity and overall survival. Mol Oncol. 2020;14(6):1207-23. 
157. Yoshikawa Y, Kuribayashi K, Minami T, Ohmuraya M, Kijima T. Epigenetic alterations and biomarkers for immune checkpoint inhibitors-current standards and future perspectives in malignant pleural mesothelioma treatment. Front Oncol. 2020;10:554570.

158. Wrangle J, Wang W, Koch A, Easwaran H, Mohammad HP, Vendetti F, Vancriekinge W, Demeyer T, Du Z, Parsana P, et al. Alterations of immune response of non-small cell lung cancer with azacytidine. Oncotarget. 2013;4(11):2067-79.

159. Tsai HC, Li H, Van Neste L, Cai Y, Robert C, Rassool FV, Shin JJ, Harbom KM, Beaty R, Pappou E, et al. Transient low doses of DNA-demethylating agents exert durable antitumor effects on hematological and epithelial tumor cells. Cancer Cell. 2012;21(3):430-46.

160. Wang C, Kulkarni P, Salgia R. Combined checkpoint inhibition and chemotherapy: new era of 1 (st)-line treatment for non-small-cell lung cancer. Mol Ther Oncolytics. 2019;13:1-6

161. Woods DM, Sodré AL, Villagra A, Sarnaik A, Sotomayor EM, Weber J. HDAC inhibition upregulates PD-1 ligands in melanoma and augments immunotherapy with PD-1 blockade. Cancer Immunol Res. 2015;3(12):1375-85.

162. Terranova-Barberio M, Thomas S, Ali N, Pawlowska N, Park J, Krings G, Rosenblum MD, Budillon A, Munster PN. HDAC inhibition potentiates immunotherapy in triple negative breast cancer. Oncotarget. 2017:8(69):114156-72.

163. Hicks KC, Fantini M, Donahue RN, Schwab A, Knudson KM, Tritsch SR, Jochems C, Clavijo PE, Allen CT, Hodge JW, et al. Epigenetic priming of both tumor and NK cells augments antibody-dependent cellular cytotoxicity elicited by the anti-PD-L1 antibody avelumab against multiple carcinoma cell types. Oncoimmunology. 2018;7(11):e1466018.

164. Wang H, Fu C, Du J, He R, Yin X, Li H, Li X, Li K, Zheng L, Liu Z, et al. Enhanced histone $\mathrm{H} 3$ acetylation of the PD-L1 promoter via the COP1/C-Jun/HDAC3 axis is required for PD-L1 expression in drug-resistant cancer cells. J Exp Clin Cancer Res. 2020;39(1):29.

165. Bensaid D, Blondy T, Deshayes S, Dehame V, Bertrand P, Grégoire M, Errami M, Blanquart C. Assessment of new HDAC inhibitors for immunotherapy of malignant pleural mesothelioma. Clin Epigenet. 2018;10:79.

166. LaFave LM, Béguelin W, Koche R, Teater M, Spitzer B, Chramiec A, Papalexi E, Keller MD, HricikT, Konstantinoff K, et al. Loss of BAP1 function leads to EZH2-dependent transformation. Nat Med. 2015;21(11):1344-9.

167. Gounder MM, Zhu G, Roshal L, Lis E, Daigle SR, Blakemore SJ, Michaud NR, Hameed M, Hollmann TJ. Immunologic correlates of the abscopal effect in a SMARCB1/INI1-negative poorly differentiated chordoma after EZH2 inhibition and radiotherapy. Clin Cancer Res. 2019;25(7):2064-71.

168. Zauderer MG, Szlosarek PW, Le Moulec S, Popat S, Taylor P, Planchard D, Scherpereel A, Jahan TM, Koczywas M, Forster M, et al. Safety and efficacy of tazemetostat, an enhancer of zeste-homolog 2 inhibitor, in patients with relapsed or refractory malignant mesothelioma. J Clin Oncol. 2020;38(15):9058-9058.

169. Hamaidia M, Gazon H, Hoyos C, Hoffmann GB, Louis R, Duysinx B, Willems L. Inhibition of EZH2 methyltransferase decreases immunoediting of mesothelioma cells by autologous macrophages through a PD-1-dependent mechanism. JCI Insight. 2019:4:18.

170. Tallón de Lara P, Cecconi V, Hiltbrunner S, Yagita H, Friess M, Bode B, Opitz I, Vrugt B, Weder W, Stolzmann P, et al. Gemcitabine synergizes with immune checkpoint inhibitors and overcomes resistance in a preclinical model and mesothelioma patients. Clin Cancer Res. 2018;24(24):6345-54

171. Guazzelli A, Meysami P, Bakker E, Demonacos C, Giordano A, KrsticDemonacos M, Mutti L. BAP1 status determines the sensitivity of malignant mesothelioma cells to gemcitabine treatment. Int J Mol Sci. 2019;20:2.

172. Okonska A, Bühler S, Rao V, Ronner M, Blijlevens M, van der MeulenMuileman IH, de Menezes RX, Wipplinger M, Oehl K, Smit EF, et al. Functional genomic screen in mesothelioma reveals that loss of function of BRCA1-associated protein 1 induces chemoresistance to ribonucleotide reductase inhibition. Mol Cancer Ther. 2020;19(2):552-63.

173. Jung KH, Park JW, Lee JH, Lee EJ, Moon SH, Cho YS, Lee KH. (89)Zr labeled anti-PD-L1 antibody PET monitors gemcitabine therapyinduced modulation of tumor PD-L1 Expression. J Nucl Med. 2020.
174. Gray SG, Baird AM, O'Kelly F, Nikolaidis G, Almgren M, Meunier A, Dockry E, Hollywood D, Ekstrom TJ, Perry AS, et al. Gemcitabine reactivates epigenetically silenced genes and functions as a DNA methyltransferase inhibitor. Int J Mol Med. 2012;30(6):1505-11.

175. Fares CM, Van Allen EM, Drake CG, Allison JP, Hu-Lieskovan S. Mechanisms of resistance to immune checkpoint blockade: why does checkpoint inhibitor immunotherapy not work for all patients? Am Soc Clin Oncol Educ Book. 2019;39:147-64.

176. Yang Y, Feng R, Wang YZ, Sun HW, Zou QM, Li HB. Toll-like receptors: triggers of regulated cell death and promising targets for cancer therapy. Immunol Lett. 2020;223:1-9.

177. Wörnle M, Sauter M, Kastenmüller K, Ribeiro A, Roeder M, Mussack T, Ladurner R, Sitter T. Role of viral induced vascular endothelial growth factor (VEGF) production in pleural effusion and malignant mesothelioma. Cell Biol Int. 2009;33(2):180-6.

178. Stone GW, Barzee S, Snarsky V, Santucci C, Tran B, Kornbluth RS. Regression of established $A B 1$ murine mesothelioma induced by peritumoral injections of $\mathrm{CpG}$ oligodeoxynucleotide either alone or in combination with poly(l:C) and CD40 ligand plasmid DNA. J Thorac Oncol. 2009:4(7):802-8.

179. Broomfield SA, van der Most RG, Prosser AC, Mahendran S, Tovey MG, Smyth MJ, Robinson BW, Currie AJ. Locally administered TLR7 agonists drive systemic antitumor immune responses that are enhanced by antiCD40 immunotherapy. J Immunol. 2009;182(9):5217-24.

180. Combaz-Lair C, Galateau-Sallé F, McLeer-Florin A, Le Stang N, DavidBoudet L, Duruisseaux M, Ferretti GR, Brambilla E, Lebecque S, Lantuejoul S. Immune biomarkers PD-1/PD-L1 and TLR3 in malignant pleural mesotheliomas. Hum Pathol. 2016;52:9-18.

181. Champiat S, Dercle L, Ammari S, Massard C, Hollebecque A, Postel-Vinay S, Chaput N, Eggermont A, Marabelle A, Soria JC, et al. Hyperprogressive disease is a new pattern of progression in cancer patients treated by anti-PD-1/PD-L1. Clin Cancer Res. 2017;23(8):1920-8.

182. Frelaut M, Le Tourneau C, Borcoman E. Hyperprogression under immunotherapy. Int J Mol Sci. 2019;20:11.

183. Fuentes-Antras J, Provencio M, Diaz-Rubio E. Hyperprogression as a distinct outcome after immunotherapy. Cancer Treat Rev. 2018;70:16-21.

184. Frelaut M, du Rusquec P, de Moura A, Le Tourneau C, Borcoman E. Pseudoprogression and hyperprogression as new forms of response to immunotherapy. BioDrugs. 2020;34(4):463-76.

185. Barnet MB, Zielinski RR, Warby A, Lewis CR, Kao S. Pseudoprogression associated with clinical deterioration and worsening quality of life in malignant pleural mesothelioma. J Thorac Oncol. 2018;13(1):e1-2.

186. Popat S. Hyperprogression with immunotherapy: Is it real? Cancer. 2019;125(8):1218-20.

187. Ferdinandus J, Barbato F, Chodyla M, Fendler WP, Kessler L, Pomykala KL, Metzenmacher M, Krefting F, Hager T, Umutlu L, et al. Volumetric PET response assessment outperforms conventional criteria in patients receiving high-dose pembrolizumab for malignant mesothelioma. J Nucl Med. 2020.

188. Topalian SL, Taube JM, Pardoll DM. Neoadjuvant checkpoint blockade for cancer immunotherapy. Science. 2020;367:6477.

189. Stein JE, Lipson EJ, Cottrell TR, Forde PM, Anders RA, Cimino-Mathews A, Thompson ED, Allaf ME, Yarchoan M, Feliciano J, et al. Pan-tumor pathologic scoring of response to PD-(L)1 blockade. Clin Cancer Res. 2020;26(3):545-51.

190. Borrelli EP, McGladrigan CG. A review of pharmacologic management in the treatment of mesothelioma. Curr Treat Options Oncol. 2021:22(2):14.

191. Toyokawa G, Takenoyama M, Hirai F, Toyozawa R, Inamasu E, Kojo M, Morodomi Y, Shiraishi Y, Takenaka T, Yamaguchi M, et al. Gemcitabine and vinorelbine as second-line or beyond treatment in patients with malignant pleural mesothelioma pretreated with platinum plus pemetrexed chemotherapy. Int J Clin Oncol. 2014;19(4):601-6.

192. Stebbing J, Powles T, McPherson K, Shamash J, Wells P, Sheaff MT, Slater S, Rudd RM, Fennell D, Steele JP. The efficacy and safety of weekly vinorelbine in relapsed malignant pleural mesothelioma. Lung Cancer. 2009;63(1):94-7.

193. Keenan TE, Burke KP, Van Allen EM. Genomic correlates of response to immune checkpoint blockade. Nat Med. 2019;25(3):389-402. 
194. Kim H, Liew D, Goodall S. Cost-effectiveness and financial risks associated with immune checkpoint inhibitor therapy. Br J Clin Pharmacol. 2020;86(9):1703-10.

195. Brockwell NK, Alamgeer M, Kumar B, Rivalland G, John T, Parker BS Preliminary study highlights the potential of immune checkpoint inhibitors in sarcomatoid mesothelioma. Transl Lung Cancer Res. 2020;9(3):639-45.

\section{Publisher's Note}

Springer Nature remains neutral with regard to jurisdictional claims in published maps and institutional affiliations.
Ready to submit your research? Choose BMC and benefit from:

- fast, convenient online submission

- thorough peer review by experienced researchers in your field

- rapid publication on acceptance

- support for research data, including large and complex data types

- gold Open Access which fosters wider collaboration and increased citations

- maximum visibility for your research: over $100 \mathrm{M}$ website views per year

At BMC, research is always in progress.

Learn more biomedcentral.com/submissions 